\title{
Permeability Enhancement in
} Fine-Grained Sediments by Chemically Induced Clay Fabric Shrinkage

Ananda M. Wijesinghe, PI, E\&E-EvSD

Edward J. Kansa, Co-PI, E\&E-EaSD

Brian E. Viani, Co-PI, E\&E-EvSD

Richard G. Blake, Co-PI, SSEP-ERD

Jeffery J. Roberts, E\&E-EaSD

Robert D. Huber, ME-MMED

February 10, 2004 


\section{Disclaimer}

This document was prepared as an account of work sponsored by an agency of the United States Government. Neither the United States Government nor the University of California nor any of their employees, makes any warranty, express or implied, or assumes any legal liability or responsibility for the accuracy, completeness, or usefulness of any information, apparatus, product, or process disclosed, or represents that its use would not infringe privately owned rights. Reference herein to any specific commercial product, process, or service by trade name, trademark, manufacturer, or otherwise, does not necessarily constitute or imply its endorsement, recommendation, or favoring by the United States Government or the University of California. The views and opinions of authors expressed herein do not necessarily state or reflect those of the United States Government or the University of California, and shall not be used for advertising or product endorsement purposes.

\section{Auspices Statement}

This work was performed under the auspices of the U.S. Department of Energy by University of California, Lawrence Livermore National Laboratory under Contract W-7405-Eng-48.

\section{LDRD Auspices Statement}

This research is funded by the Laboratory Directed Research and Development (LDRD) Program at Lawrence Livermore National Laboratory (LLNL) under project 03-FS-004. The LDRD Program is mandated by Congress to fund laboratory-initiated, long-term research and development (R\&D) projects in support of the DOE and national laboratories' mission areas. The Director's Office LDRD Program at LLNL funds creative and innovative R\&D to ensure the scientific vitality of the Laboratory in missionrelated scientific disciplines. 


\section{CONTENTS}

Page

$\begin{array}{lr}\text { 1. Abstract } & 1\end{array}$

2. Objective and Motivation 2

3. Scientific Basis 3

4. Experiment Design and Measurements 6

5. Results 22

6. Significance and Conclusions 31

7. Future Work $\quad 32$

8. Acknowledgments 33

9. References $\quad 34$ 


\section{LIST OF FIGURES}

Page

1. Dependence of Clay Particle Repulsion Energy on Solvent Dielectric Constant, $\varepsilon / \varepsilon_{0}$.

2. Hydraulic Conductivity of Smectite Clay vs. Ethanol Permeant Concentration

3. The Crack Front Outruns the Diffusion Front Propagating Inwards

From the Advectively Flushed External Boundary.

4A. Shrinkage Coefficient Measurement Cell (Longitudinal Cross Section)

4B. Photograph of the Shrinkage Coefficient Measurement Cell

5A. Crack Propagation and Imaging Cell (Longitudinal Cross Section)

5B. Photograph of the Crack Propagation and Imaging Cell

6. Crack Propagation Experiment Setup

7. Electrode Clusters for Fluid Property and Tracer Species Measurements 11

8. Experimental Setup for Crack Imaging by X-ray Tomography 12

9. Solvent Stream Bromide Electrode Output as a Function of Bromide Concentration and Ethanol Fraction (See Legend)

10. Water Stream Bromide Electrode Output as a Function of Bromide Concentration and Ethanol Fraction (See Legend)

11. Solvent Stream Perchlorate Electrode Output as a Function of Perchlorate Concentration and Ethanol Fraction (See Legend)

12. Water Stream Perchlorate Electrode Output as a Function of Perchlorate Concentration and Ethanol Fraction (See Legend)

13. Electrical Conductivity Probe Base Calibration Using KCI Standard Conductivity Solutions

14. Electrical Conductivity Probe Output as Function of Bromide Concentration and Ethanol Fraction (See Legend).

15. Electrical Conductivity Probe Output as Function of Perchlorate Concentration and Ethanol Fraction (See Legend).

16. Electrical Conductivity of Site 300 Water in Contact with PELBON Calcium Bentonite Clay.

17. Variation of the Dielectric Coefficient of Ethanol-Water Solutions with Ethanol Fraction.

18. Temperature Probe Output Voltage Versus Temperature.

19. Cumulative Effluent Mass Flow and Effluent Ethanol Fraction upon Crack Breakthrough

20. Photographs of Crack Patterns on the Circular Face and the Circular Edge of the Clay Disk 
21. X-Ray Tomography Images of Shrinkage Cracks Created by $100 \%$ Ethanol Perfusion Under 15 psi Confining Stress; Cross-Sections Normal to the Axis of the Clay Disk From the Water Side (200) to the Ethanol Side (390).

22. X-Ray Tomography Images of Shrinkage Cracks Created by $100 \%$ Ethanol Perfusion Under 15 psi Confining Stress; Cross-Sections Parallel to the Axis of Clay Disk: Water Side at Top of Image.

\section{LIST OF TABLES}

1. Chemicals Required for Preparation of Synthetic Site 300 Water. 13

2. Physicochemical Properties of PELBON Calcium Bentonite Clay. 14

3. Electrical Conductivity of Synthetic Site 300 Water in Contact with PELBON Clay. 18

4. Time Required for the Ethanol Diffusion Front to Traverse the Clay Layer. 23

5. Increase in Effective Permeability due to Shrinkage Induced Clay Cracking. 24 


\title{
1. ABSTRACT
}

\section{Permeability Enhancement in Fine-Grained Sediments by Chemically Induced Clay Fabric Shrinkage}

\author{
Ananda M. Wijesinghe, PI, E\&E-EnSD, Edward J. Kansa, Co-PI, E\&E-EaSD \\ Brian E. Viani, Co-PI, E\&E-EnSD, Richard G. Blake, Co-PI, SSEP-ERD \\ Jeffery J. Roberts, E\&E-EaSD, Robert D. Huber, ME-MMED
}

The National Research Council [1] identified the entrapment of contaminants in fine-grained claybearing soils as a major impediment to the timely and cost-effective remediation of groundwater to regulatory standards. Contaminants trapped in low-permeability, low-diffusivity, high-sorptivity clays are not accessible to advective flushing by treatment fluids from permeable zones, and slowly diffuse out to recontaminate previously cleaned permeable strata. We propose to overcome this barrier to effective remediation by exploiting the ability of certain nontoxic EPA-approved chemicals (e.g., ethanol) to shrink and alter the fabric of clays, and thereby create macro-porosity and crack networks in fine-grained sediments. This would significantly reduce the distance and time scales of diffusive mass transport to advectively flushed boundaries, to yield orders of magnitude reduction in the time required to complete remediation. Given that effective solutions to this central problem of subsurface remediation do not yet exist, the cost and time benefits of successful deployment of this novel concept, both as a stand-alone technology and as an enabling pre-treatment for other remedial technologies that rely on advective delivery, is likely to be very large. This project, funded as a 1-year feasibility study by LLNL's LDRD Program, is a multi-directorate, multi-disciplinary effort that leverages expertise from the Energy \& Environment Directorate, the Environmental Restoration Division, and the Manufacturing \& Materials Evaluation Division of Mechanical Engineering.

In this feasibility study, a "proof-of-principle" experiment was performed to answer the central question: "Can clay shrinkage induced by ethanol in clay-bearing sediments overcome realistic confining stresses, crack clay, and increase its effective permeability by orders of magnitude within a time that is much smaller than the time required for diffusive mass transport of ethanol in the unaltered sediment?" To this end, we performed a crack propagation experiment under confining stress on an initially watersaturated bentonite clay layer that was exposed to pure ethanol on one surface and water on the other. We measured the rate of transport of ethanol across the clay layer and found that crack breakthrough across the clay layer was accompanied by a very large sudden increase in solvent flow through the layer. Although an experimental artifact prevented measurement of the exact breakthrough time, visual evidence indicates that the clay layer cracked rapidly in this experiment. Direct evidence of the cracks provided by X-ray tomographic images provide clear proof that an extensive array of cracks was created by the ethanol-induced shrinkage. Calculations based on measured fluid pressure and flow rates, and published permeabilities of unaltered calcium bentonite clays, show that the effective permeability of the clay layer increased by a factor of $10^{9}-10^{12}$. Estimates of effective permeability based on crack dimensions measured from the X-ray tomographic images support these findings.

Further detailed experiments and analyses are needed to develop a predictive theory and a quantitative design capability for this process. We have begun work on securing the necessary support for these studies, with the ultimate objective of developing and deploying this novel concept as a practical remediation technology in the field. 


\section{OBJECTIVE AND MOTIVATION}

The objective of this project was to verify experimentally that certain organic solvents (e.g., ethanol), in contact with clay-bearing sediments under confining stress, cause sufficient shrinkage in the fabric of the sediment to create macro-porosity and crack networks that greatly increase the effective permeability of the clay, within a time that is much smaller than the time required for mass transport of the solvent by diffusion through the unaltered sediment. If the speed of alteration of fabric is itself limited by slow diffusion within the sediment, then the proposed process would take as long a time as for remediation by existing technologies whose access is limited by diffusion, and may not be feasible. We planned to resolve this central issue through a proof-of-principle experiment, and to use the results to justify additional work and funding from external sources geared to developing and deploying this process as an accelerated remediation technology for contaminated fine-grained sediments.

In the absence of advective transport, the time required to remediate the sources of pollution trapped in relatively impermeable tight zones is dominated by the slow diffusion of remedial agents into the zones, slow desorption of the contaminants from the highly sorptive clay surfaces, low solubility of the desorbed contaminant in the remedial agent, and the slow diffusion of the mobilized contaminants out of the low-permeability zones [1,2]. Because each of these mass transfer steps is very slow, the contaminants remain trapped within the sediments, are not flushed out, and are bypassed, by fluids flowing within adjacent high-permeability zones. However, the slow but continuous diffusion of contaminants from the low-permeability zones into the high-permeability zones recontaminate the previously remediated high-permeability zones. This results in costly remediation projects that require decades and even centuries $(20,60,130$ years for 1,2 and $4 \mathrm{ft}$ of contaminated clay thicknesses [1]) for complete remediation by existing methods. Although this problem is well recognized, no technology capable of cost-effectively dealing with this central problem of subsurface remediation, that renders ineffective all remediation technologies that depend on advective delivery of treatment agents, has yet been developed. Given that the pollution of large bodies of water by small amounts of toxic contaminants is the greatest threat to the nation's groundwater supply, and the largest cost component in the inventory of groundwater pollution problems, the impact of successful deployment of this technology would be very large. Although we had patented (U.S Patents 5,593,248 [3], 5,906,748 [4]) the basic concepts of the full remediation technology for overcoming the permeability, sorption and solubility barriers based on chemical

enhancement of the permeability of fine-grained sediments, the current project is the first study focused on verifying the feasibility of principal concept underlying the process. 


\section{SCIENTIFIC BASIS}

The low permeability and diffusivity of water-saturated clays and clay-bearing porous media result from the very small pore sizes and highly tortuous fluid flow pathways in the sediments. These are ultimately controlled by the arrangement and spacing within and between partially ordered groupings of individual clay platelets $(0.01-1 \mu \mathrm{m})$ into domains $(1-100$ 's $\mu \mathrm{m})$ that define the clay fabric. The electrostatic repulsive forces between the individual clay platelets, and adjacent hydration layers, that maintain the clay in a swollen state can be predicted by the DLVO theory [5,6,7] and its extensions [8]. As shown in Figure 1 , a reduction in the dielectric constant $\varepsilon / \varepsilon_{0}$ of the fluid phase, for example from 79 for water to 24 for ethanol, would cause a significant reduction in the repulsion energy of the clay platelets, and a corresponding shrinkage in the external dimensions of the clay.

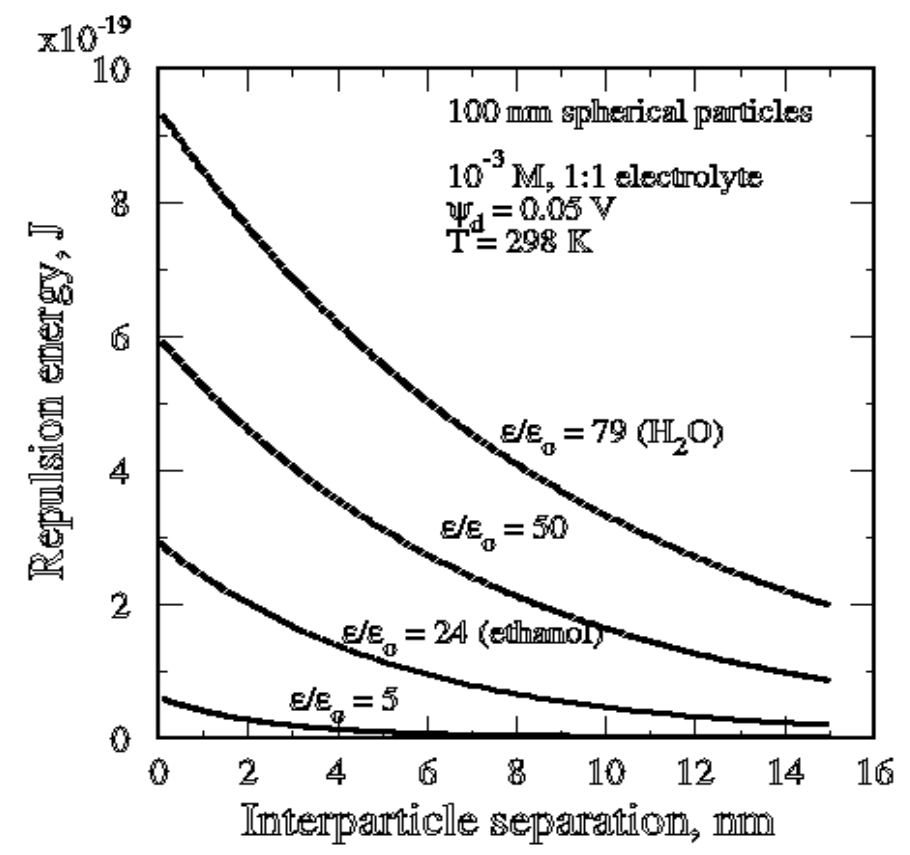

Figure 1. Dependence of Clay Particle Repulsion Energy on Solvent Dielectric Constant, $\varepsilon / \varepsilon_{0}$.

\section{Clay Shrinkage and Cracking}

The shrinkage response is usually quantified in terms of the volumetric shrinkage coefficient $\alpha$ (typically 0.1 to 0.5 for smectite clays) that when multiplied by the change in ethanol mass fraction $X_{e}$ yields the change in volume strain. A simplistic approach to cracking of the clay is to assume that the clay deforms elastically, and forms cracks when the normal effective stress induced on a plane by clay shrinkage overcomes the sum of the confining effective stress and the tensile strength of the clay. Thus, the minimum ethanol concentration required to initiate cracking can be estimated from $\alpha_{L} X_{\text {emin }}=\left(S_{0}-P_{0}\right) / E$ $+S_{\mathrm{t}} / E$, where $\alpha_{\mathrm{L}}(\approx \alpha / 3), S_{0}, P_{0}, E$ and $S_{t}$ are the linear shrinkage coefficient, total confining stress, pore fluid pressure, Young's elastic modulus, and the tensile strength of the clay, respectively. 
Hydraulic Conductivity of Smectite Clay

Vs. Ethanol Concentration

(Brown \& Thomas, 1987)



Figure 2. Hydraulic Conductivity of Smectite Clay vs. Ethanol Permeant Concentration

\section{Permeability Enhancement with Organic Solvents}

In their studies of the permeability and cracking of clays and clay soils, many investigators $[9,10,11,12,13,14,15]$ have observed dramatic increases in hydraulic conductivity (e.g., Figure 2) accompanied by crack formation $[11,16,17,18]$ when clays are permeated by certain organic solvents. For a uniform linear array of parallel cracks of width $w_{C}$ and crack spacing $h_{C}$, the average crack width can be calculated from $w_{C} / h_{C}=\alpha_{L}\left(X_{e}-X_{e m i n}\right)$ for an ethanol mass fraction $X_{e}>X_{e m i n}$. Assuming viscous Poiseuille flow, the hydraulic conductivities of the cracks and the adjoining shrunken clay can be added to yield $\mathrm{K}_{\mathrm{C}}=\mathrm{K}_{\mathrm{UC}}\left\{\left(1-\alpha \mathrm{X}_{\mathrm{e}} / \phi_{\mathrm{UC}}\right) /\left(1-\alpha \mathrm{X}_{\mathrm{e}}\right)\right\}^{\mathrm{n}}\left(\mathrm{w}_{\mathrm{C}} / \mathrm{h}_{\mathrm{C}}\right)+\left(\mathrm{h}_{\mathrm{C}}{ }^{2} / 12\right)\left(\mathrm{w}_{\mathrm{C}} / \mathrm{h}_{\mathrm{C}}\right)^{3}$ for the effective permeability $\mathrm{K}_{\mathrm{C}}$ of the cracked clay, where $\mathrm{n}$ is the power law index for permeability as a function of porosity, and uvc $_{\mathrm{u}}$ is the porosity of the uncracked clay. For an uncracked clay permeability $K_{U C}=1.0 \times 10^{-13} \mathrm{~m}^{2}$, a crack spacing $\mathrm{h}_{\mathrm{C}}=$ $0.1 \mathrm{~m}$, and $\mathrm{w}_{\mathrm{C}} / \mathrm{h}_{\mathrm{C}}=0.01$, a very large effective permeability increase ratio of $\mathrm{K}_{\mathrm{C}} / \mathrm{K}_{U \mathrm{UC}} \approx 10,000$ between the cracked and uncracked clays is obtained.

\section{Mass Transfer Rate Enhancement:}

The creation of cracks within the clay body sub-divides the clay mass into an array of cracked cells of size $h_{C}$ whose crack boundaries can now be advectively flushed. The time required for diffusive transport in the uncracked material can be estimated from $T_{U C}=d_{U C}{ }^{2} /\left[D_{w} /\left(\tau_{U C} R_{U C}\right)\right]$, where $d_{U C}$ is the depth of contamination, $D_{w}$ is the diffusion coefficient in bulk water, and $\tau_{U c}$ and $R_{U c}$ are the tortuosity and retardation coefficient of the uncracked clay, respectively. Similarly, the diffusion time for the treated, cracked and shrunken clay is given by $T_{C}=h_{C}{ }^{2} /\left[4 D_{e} /\left(\tau_{C} R_{C}\right)\right]$, where half the crack spacing is the new distance to the crack boundary. A very significant mass transfer speedup ratio of 1,200 is obtained from $T_{u C} / T_{C}=4 .\left(d_{u C} / h_{C}\right)^{2} .\left(D_{e} / D_{w}\right) \cdot\left(\tau_{u C} / \tau_{C}\right)$. $\left(R_{U C} / R_{C}\right)$, assuming a crack spacing of $0.1 \mathrm{~m}$, a depth of contaminant penetration of $1 \mathrm{~m}$, and diffusion coefficient, tortuosity and retardation coefficient ratios between the cracked and uncracked clays of 2,2 and $1 / 3$, respectively. 


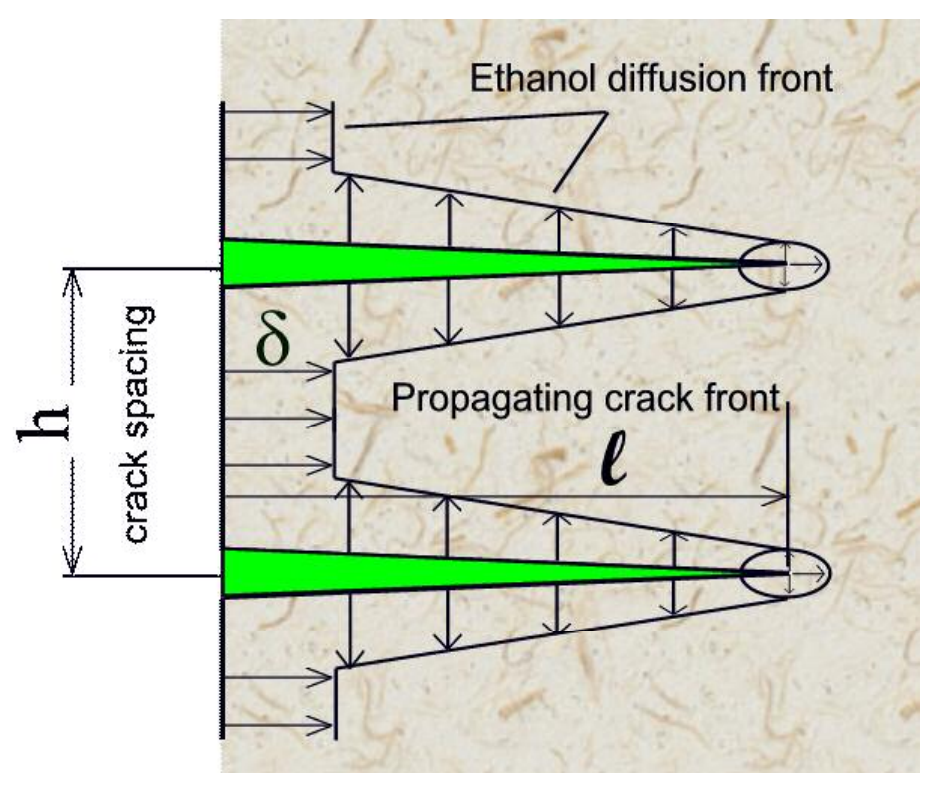

Figure 3: The Crack Front Outruns the Diffusion Front Propagating Inwards From the Advectively Flushed External Boundary.

\section{Crack Propagation Speed and Crack Spacing}

The feasibility of the proposed remediation technology depends not only on the increase in mass transfer rate once the crack network has been created, but also on the speed at which the crack network itself can be created. It has been reported in the literature that thick clay liners used to impound organic solvent wastes within retention ponds quickly fail by the rapid propagation of fractures through the liners, at a speed that is much faster than the rate of penetration of the diffusion front from the external boundary. None of the laboratory studies on the failure of clay liners [9-16], and the effect of solvents on the permeability of clays, have measured the crack propagation velocity or provided a mechanistic explanation for the rapidity of clay liner failures. We believe that the crack speed depends only on the localized diffusion and shrinkage strains at the crack tip itself, and not on the accumulated shrinkage strains elsewhere. As long as the concentration of the cracking agent at the crack tip is above the minimum required to overcome the effective confining stress and the tensile strength as previously described, the crack will continue to extend, with advection within the crack feeding the cracking agent to the crack tip. In contrast, the crack width depends on the extent of penetration of the solvent from the crack into the clay, and need not be large for substantial increases in permeability to be realized. Our theoretical models provide an explanation for this behavior, with the crack propagation velocity depending on the excess shrinkage strain $\alpha_{L}\left(X_{e}-X_{e m i n}\right)$ at the crack tip. The crack spacing would be determined by the balance between crack-surface energy and strain energy as well as the presence of planes of weakness within the clay body related to "domain-level" spatial variations within its organizational structure. 


\section{EXPERIMENT DESIGN AND MEASUREMENTS}

\section{Experiment Design}

The work plan was focused on performing a proof-of-principle experiment on a clay material prepared from a commercially available calcium bentonite, at several ethanol concentrations and confining stress levels. To maintain reproducibility, a buffered synthetic groundwater with composition similar to the groundwater at LLNL's Site 300 was used (see below).

We evaluated two imaging techniques, namely X-ray tomography and ultrasonic tomography, for feasibility in imaging the cracks that would be formed in the clays by ethanol induced shrinkage. We estimated the widths of the crack that would be formed would lie in the range of 1-100 $\mu \mathrm{m}$. To test the feasibility of detecting the cracks by each technique, a double blind test was performed by imaging two identical $2.54 \mathrm{~cm}(1 \mathrm{in})$ diameter cylindrical plastic bottles containing bentonite clay samples. One of the two bottles contained a rectangular piece of wetted filter paper inserted longitudinally to simulate a fracture, but the experimenters were not informed of which bottle contained the fracture. The X-ray imaging method was able to identify both the bottle and the orientation of the fracture in the bottle, whereas the low-frequency $(12 \mathrm{MHz})$ ultrasonic technique was unable to do so due to excessive noise in the detected signal. Therefore, it was decided to not use the ultrasonic method in view of the excellent results obtained with the X-ray imaging technique, although higher-frequency, higher-resolution, ultrasonic imaging systems (high resolution $50 \mathrm{MHz}$ rotating-detector transmission system, and a very high resolution $150 \mathrm{MHz}$ pulse-echo reflection system, all with associated CAT software for generating 3D images), that are available could have performed better than the low frequency system.

The first task was to design the shrinkage strain and crack propagation experimental test cells using estimated mechanical clay properties and ethanol-clay interaction properties. The analyses for designing the test cells were performed using approximate analytical poroelastic-plastic models.

\section{Clay Shrinkage Measurement Cell Design}

The design of the test cell for measuring the shrinkage coefficient is shown in Figure 4. In this design, the primary goal was to measure the volume shrinkage coefficient time under applied confining stress within a reasonable time, without allowing any cracks to form in the interior of the clay sample. The original hydrostatic cell design was replaced by the one-dimensional compression cell design shown in Figure 4 to permit a cell design that would enable the clay material to be rapidly permeated by the ethanol solvent, in the absence of cracks. To facilitate transport of ethanol, the clay sample was formed of sixteen cylindrical clay disks that were $0.3175 \mathrm{~cm}(0.125 \mathrm{in})$ high and $4.7625 \mathrm{~cm}(1.875 \mathrm{in})$ in diameter. The clay disks were assembled into a $5.08 \mathrm{~cm}$ (2 in) high stack and separated from one another by disks of tangential flow filter paper. Each tangential flow filter paper has a low permeability layer bonded to high permeability layer. Two such papers, with the high permeability sides placed back-to-back, were sandwiched between two clay disks to prevent clay particles from clogging the tangential flow path along the high permeability filter sides, while permitting fluids to enter and exit the high permeability tangential flow channel from the clay across the low permeability surfaces. The sandwiched filter papers were extended outside the stack as tabs on alternate sides and were connected to two separate filter papers that served as the inlet and exit manifolds. The ethanol solvent entered through the inlet manifold, while the pore water in the clay was expelled through the exit manifold. Under the confining stress applied to the loading piston using compressed air, the inlet and exit manifolds made intimate contact with the ethanol inlet and water exit ports. Because clay flows plastically at low stresses, the stress state within the clay was assumed to be approximately isotropic. The volume of the clay in the stack of clay disks was calculated by making a small correction for the volume of filter paper. The change in this volume was computed from the axial displacement measured by the digital displacement transducer. The cell was constructed using transparent PVC material that was resistant to degradation by the ethanol solvent. 


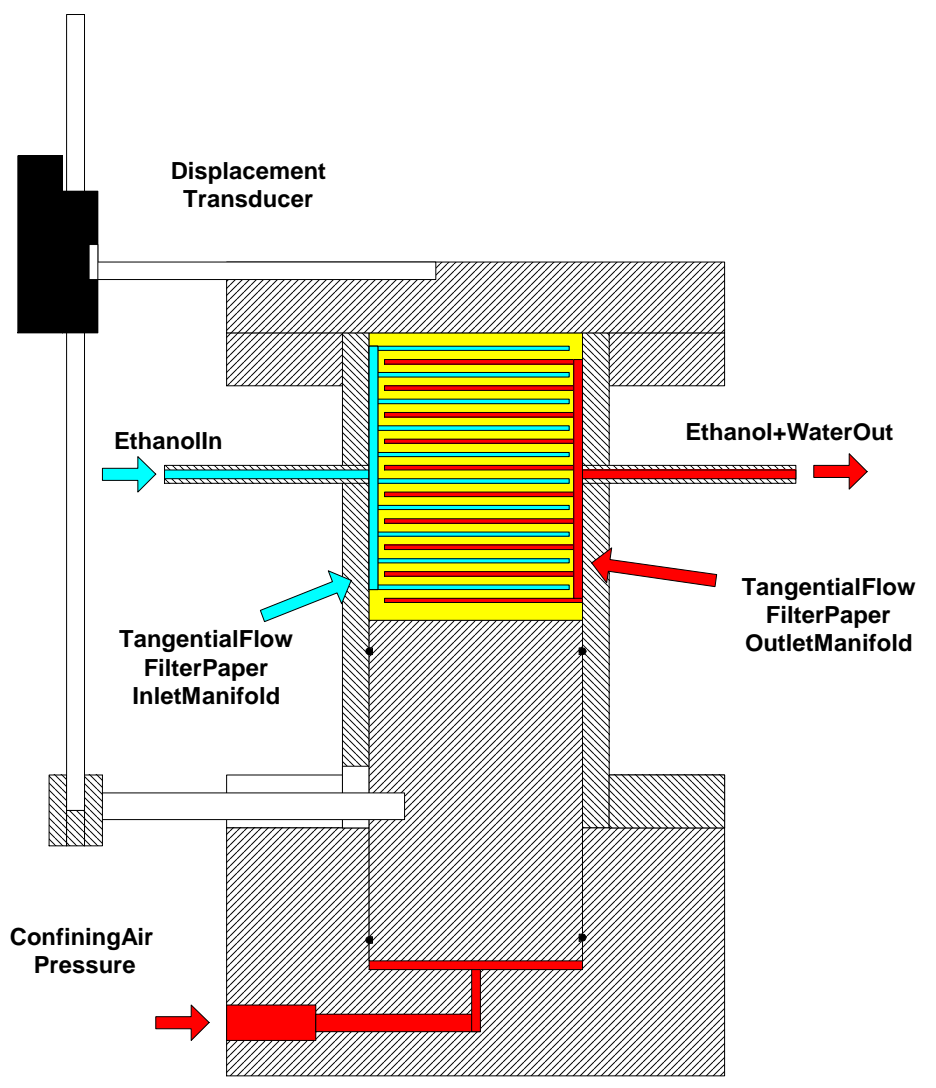

Figure 4A. Shrinkage Coefficient Measurement Cell (Longitudinal Cross Section)

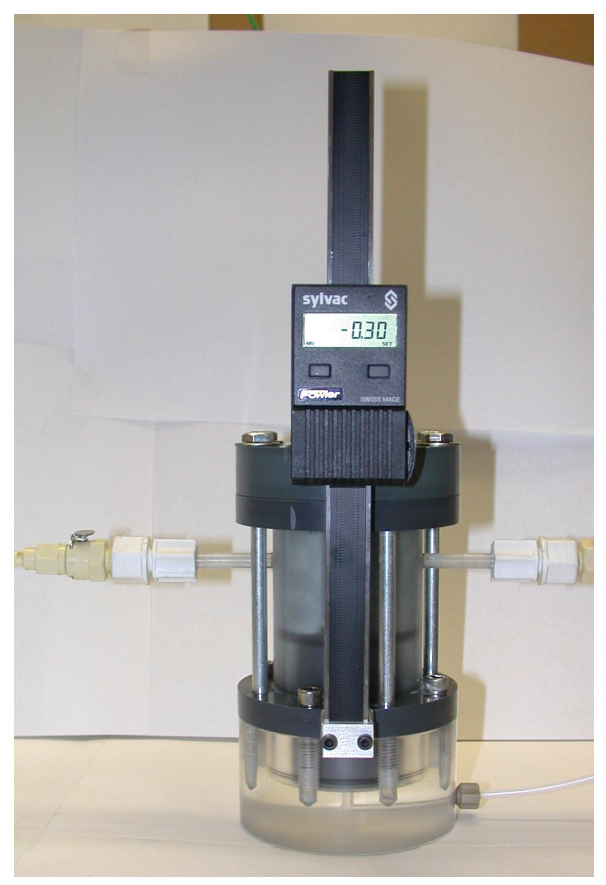

Figure 4B. Photograph of the Shrinkage Coefficient Measurement Cell 


\section{Crack Propagation and Imaging Cell Designs}

The crack propagation cell, shown in Figures $5 \mathrm{~A}$ and $5 \mathrm{~B}$, was also constructed of transparent PVC that is immune to degradation by ethanol. It consists of a $1 \mathrm{~cm}$ thick, $4.7625 \mathrm{~cm}$ (1.875in) diameter clay layer sandwiched between two chambers filled with quartz silica sand. The same one-dimensional confining stress was applied to both sides of the clay through the sand layers using pistons driven by compressed air, causing the clay to flow plastically and make contact with the circular external wall of the cell.

The main difficulty in designing this cell was to devise a means of preventing the shrinking clay from separating from the external cell wall and opening a flow path across the clay disk at the clay-wall interface. The solution we devised to overcome this difficulty was to apply a "pinching" normal stress on the clay on an annular region along the wall that is higher than the confining stress applied elsewhere on the flat faces of the clay layer. The radial stress in the interior of the clay disk would then be lower than the radial stress at the wall induced by the pinching normal stress. Thus, the shrinkage cracks would be forced to form in the interior of the clay at the center of the disk, before contact with the wall is lost. This was achieved by a novel design in which the loading piston applying the confining stress at the bottom surface of the clay disk was incorporated within a third annular "pinching pressure" piston loaded by a separate compressed air supply. In tests performed at $P_{c}=15$ psi confining stress, a pinching air pressure of $P_{p}=17$ psi was maintained, yielding a pinching normal stress equal to $P_{c}+\left(P_{p}-P_{c}\right) /\left(1-\left(R_{i} / R_{o}\right)^{\wedge} 2\right)=25.5$ psi at the wall $\left(R_{i}=4.28625 \mathrm{~cm}(1.6875 \mathrm{in}), R_{0}=4.7625 \mathrm{~cm}(1.875 \mathrm{in})\right)$. At these applied pressures, this piston-within-a-piston cell design performed excellently in our tests without any observed leaks at the claywall interface.

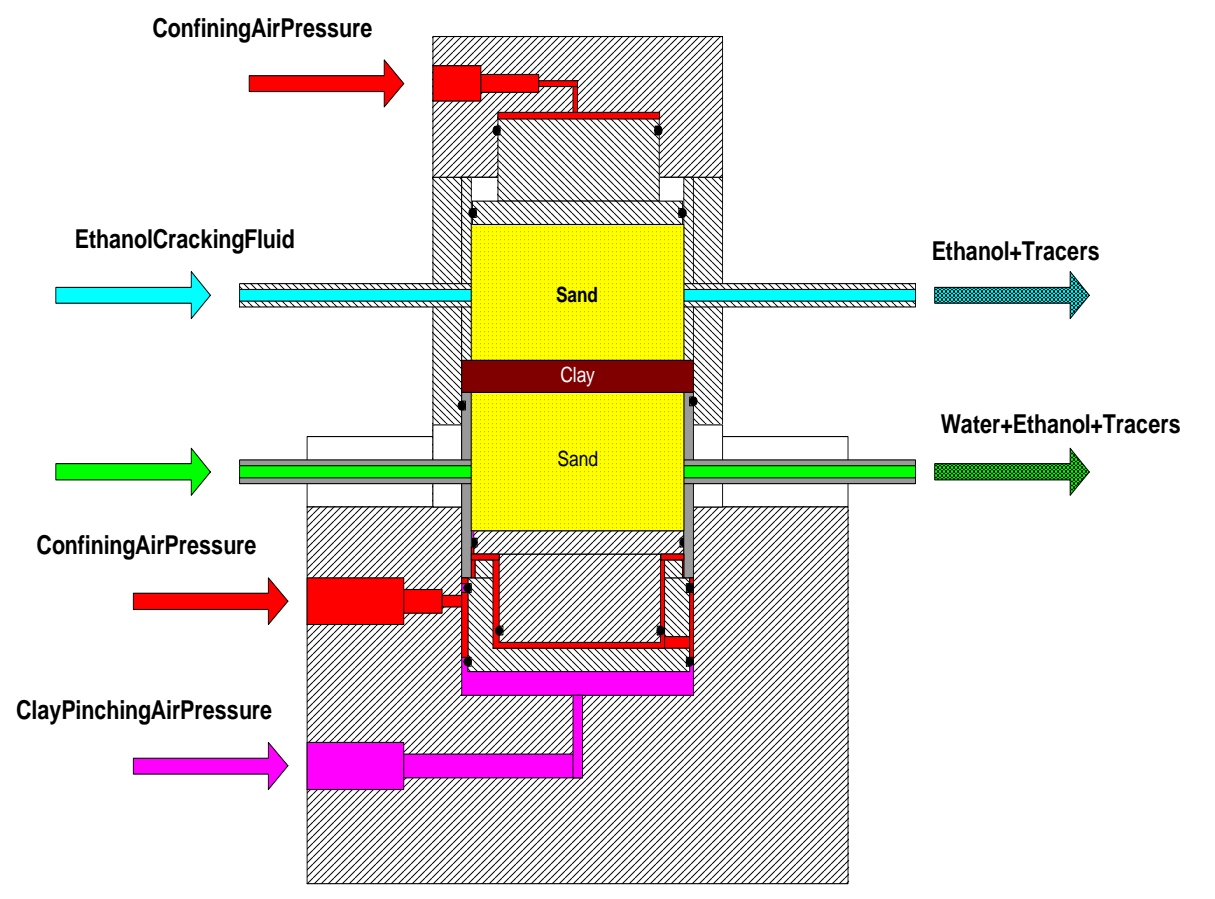

Figure 5A. Crack Propagation and Imaging Cell (Longitudinal Cross Section) 


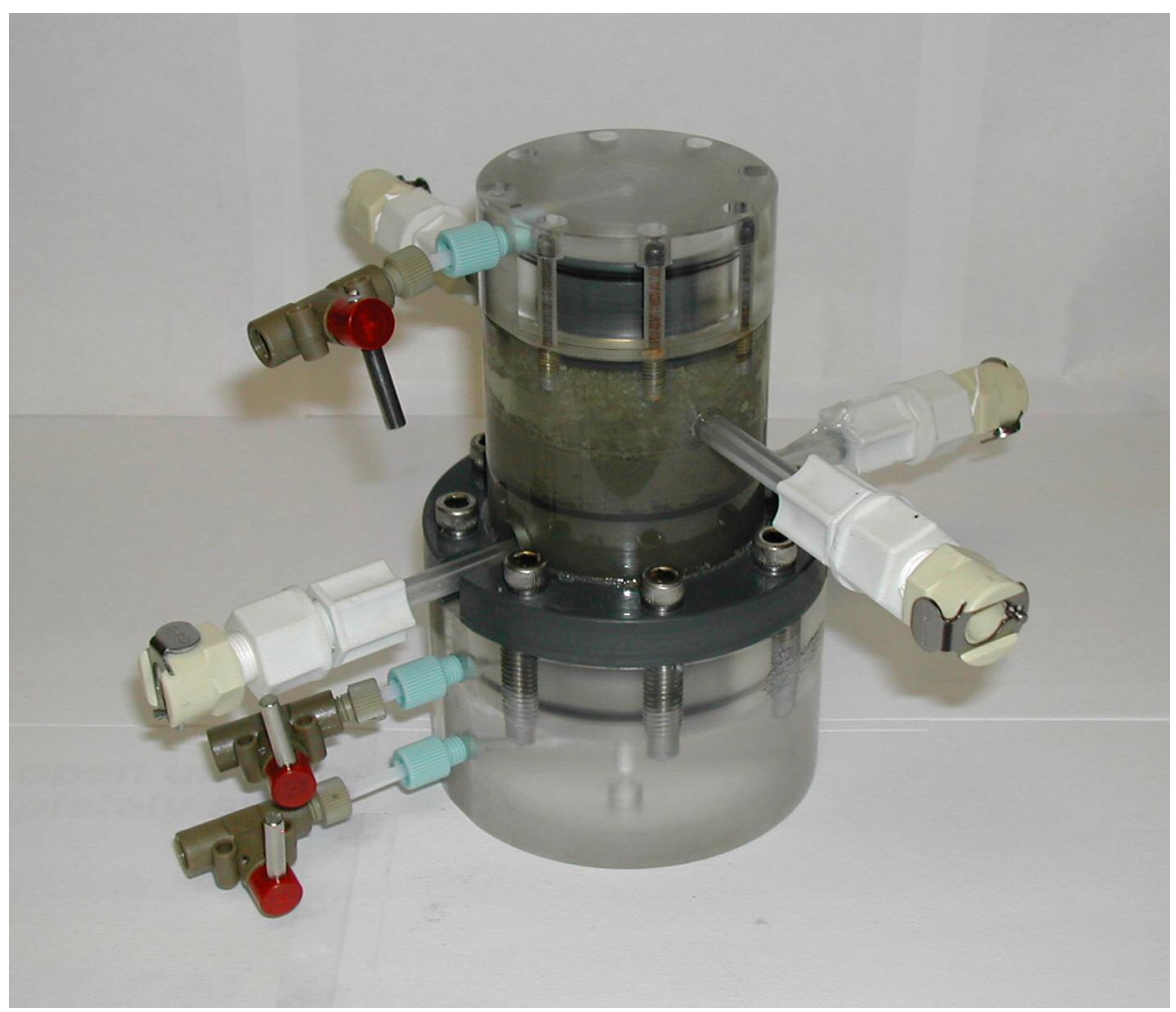

Figure 5B. Photograph of the Crack Propagation and Imaging Cell

Another important design consideration was the avoidance of metallic fixtures in the imaging window occupied by the clay layer, and to utilize thin cell walls to permit unhindered transmission of the $X$ ray beam. The compressed air connections were equipped with miniature ball valves, and spring-loaded self-sealing snap connectors were installed on the fluid access ports so that all flow lines could be disconnected and reconnected at will for transportation of the cell to the X-ray imaging station.

\section{Experiment Setup and Flow Stream Instrumentation}

The experimental setup for the main crack propagation and imaging experiment is shown in Figure 6. Each of the two quartz sand filled fluid chambers has an "upstream" and a "downstream" fluid port. These are connected to constant head tanks that are equipped with spillways to maintain a constant hydraulic head independent of the fluid flow rate. A circular disk of bentonite, $1 \mathrm{~cm}$ thick and $4.7625 \mathrm{~cm}$ (1.875 in) diameter, was molded using the clay paste (with $\mathrm{NaClO}_{4}$ tracer) prepared as described below in the Experimental Materials section. It was installed in the cell with the flow cell assembled from the bottom up. The fluid and air pressure lines were connected as shown in Figure 6 with the downstream flow streams routed through two measurement electrode clusters. 


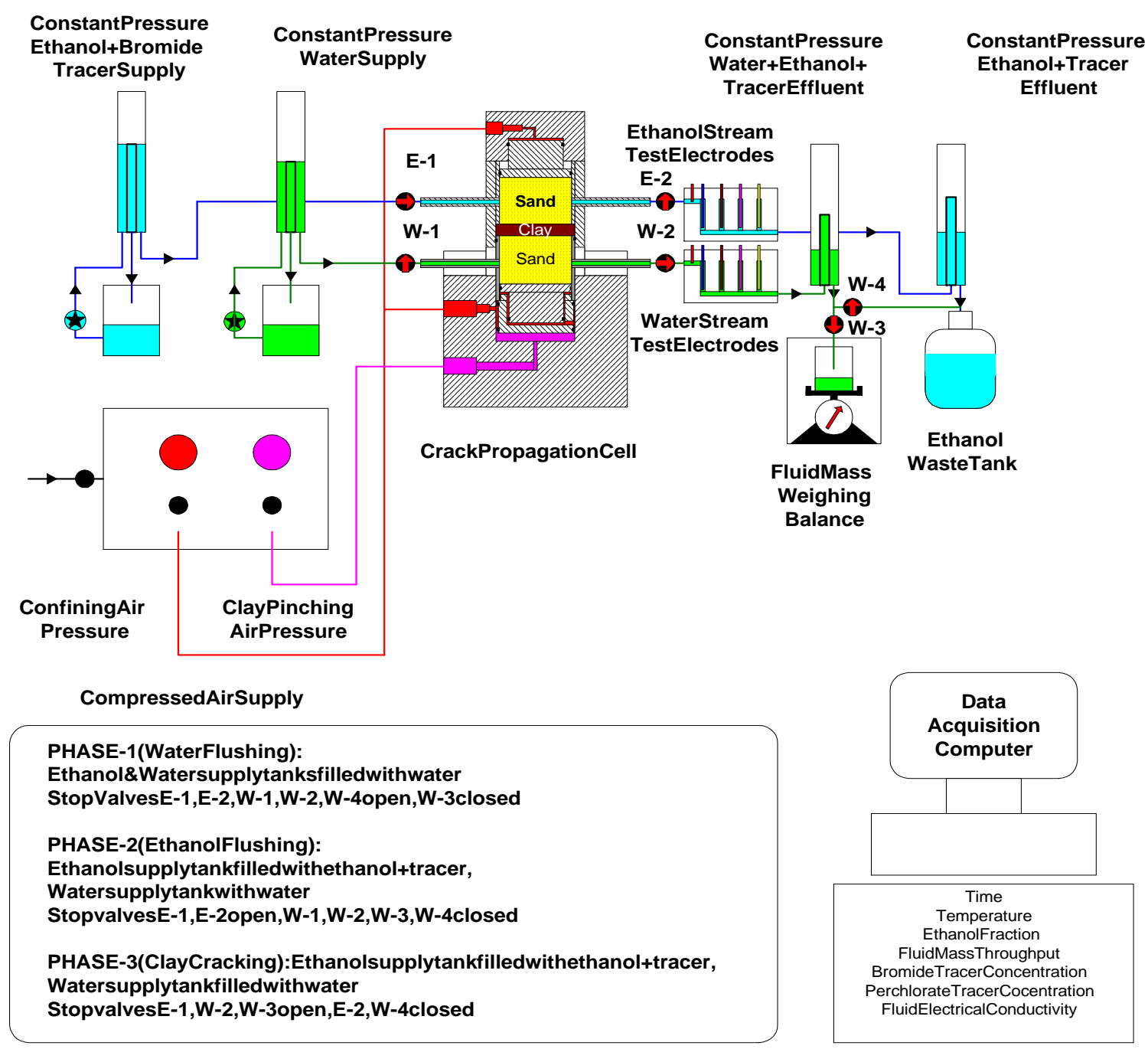

Figure 6. Crack Propagation Experiment Setup

The details of the custom-built ethanol and water stream electrode clusters for measuring the ethanol-water fractions, tracer species concentrations, electrical conductivity and temperature are shown in Figure 7. The electrode cluster in the downstream ethanol stream contains four wells with an electrode installed in each well. The first electrode is a cylindrical annular flow capacitance sensor for measuring the solvent-water fraction, the second is a perchlorate ion-selective electrode, the third a bromide ion-selective electrode, and the last well is occupied by a semiconductor temperature probe. Likewise, the downstream fluid in the water stream flows through a second electrode cluster containing four wells with installed electrodes. The first three electrodes are the same as for the solvent stream with the first being a cylindrical capacitance sensor for measuring the solvent-water fraction, the second a perchlorate ionselective electrode, and the third a bromide ion-selective electrode. The last electrode measures the electrical conductivity of the water stream. The ion-selective bromide and perchlorate electrodes are commercially available units providing a DC voltage output. The capacitance electrodes, which we specially designed and built for this experiment, measures the ethanol-water mass fraction by sensing the difference between the ethanol-water mixture and the dielectric coefficients of the two pure liquids. The electrical conductance measurements were made using inert platinum electrodes, and a $1,100 \mathrm{~Hz}$ sinusoidal AC supply voltage to avoid the effects of polarization of the electrodes. 


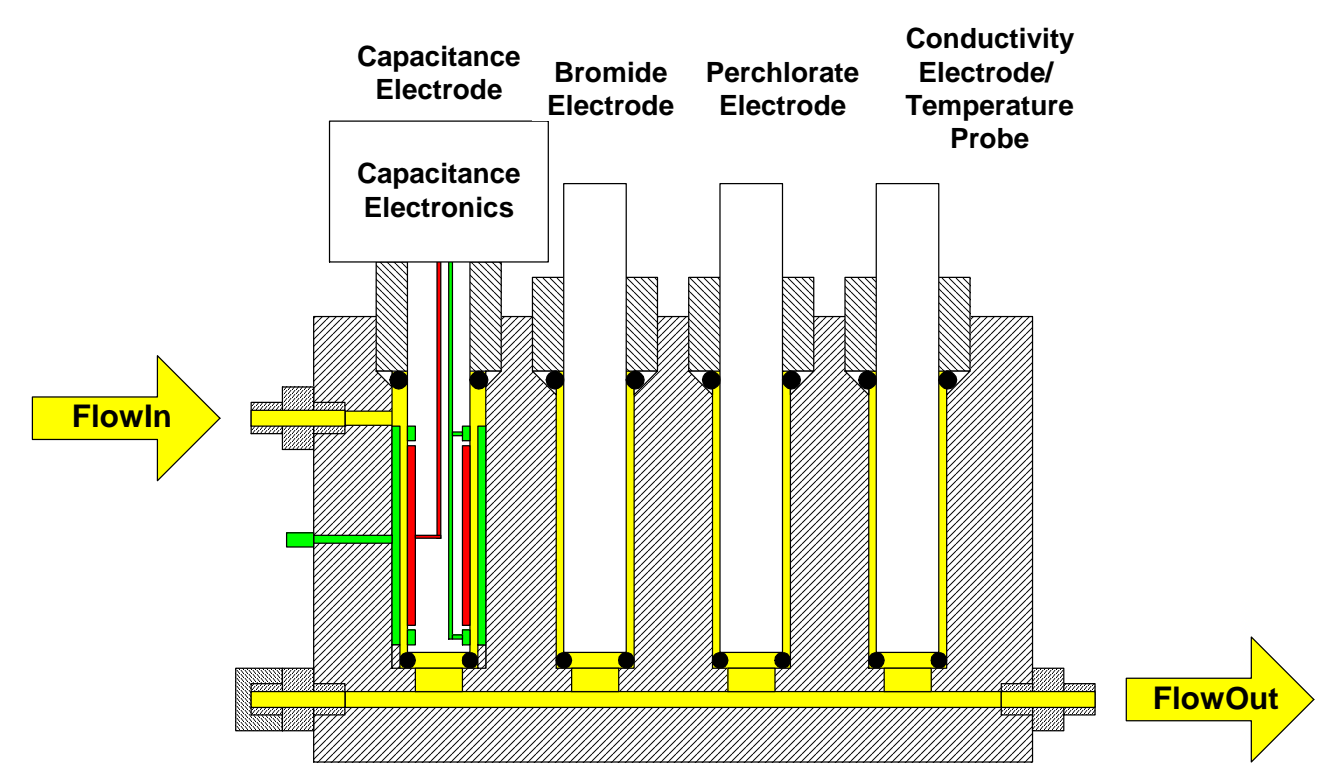

Figure 7. Electrode Clusters for Fluid Property and Tracer Species Measurements

The solvent stream exiting the solvent stream electrode cluster was routed to a constant head tank with a spillway and the spillway effluent was collected in a waste liquid storage tank. Likewise, the water stream exiting the water stream electrode cluster was routed to another constant head spill tank that was placed on an electronic mass balance with serial data output. The mass balance measures the cumulative mass of liquid flowing in the downstream water stream. The purpose of the constant head tanks with spillways is to maintain a small but steady pressure difference between the upstream and downstream chambers in the crack propagation cell, independent of variations in the flow rate. This pressure difference was initially maintained at the low value of $0.0723 \mathrm{psi}$ ( 2 in of water), but was later increased to $0.510 \mathrm{psi}$ (14.125 in of water) to overcome blockage of the downstream water stream exit line by air bubbles. This small increase in the applied pressure gradient would not lead to crack formation by hydraulic fracturing, because the radial compressive stress that must be overcome by the pore fluid pressure to cause fracturing is of the order of the confining pressure (15 psi), a value that is much larger than the hydraulic pressure difference applied across the clay layer.

The signal outputs from all electrodes in the measurement electrode clusters, and from the mass balance, were collected by a data acquisition (DAQ) system that was capable of acquiring both analog and digital data on multiple channels. The DAQ was developed using low cost external data acquisition boards connected via USB ports to a computer workstation. The DC voltage outputs of the ion-selective electrodes were pre-amplified by differential instrumentation amplifiers before being sent to the DAQ system. Serial RS232 output devices, such as the mass balance (and the digital displacement transducer in the shrinkage coefficient experiment), were connected to the computer using RS232 to USB multi-port converters. For convenience and reduced cost, we wrote a custom data acquisition software package in the Visual Basic for Applications (VBA) language that is native to the Microsoft Office software package, to directly input the measured data into a Microsoft Excel spreadsheet. The capability to backup the acquired data to a remote computer, and to send e-mail alerts to the investigators upon the occurrence of preprogrammed events such as the anticipated solvent breakthrough across the clay layer, were programmed into this software package.

After assembling and connecting all fluid lines, the confining air pressure was applied followed by the pinching air pressure. The bottom chamber was filled and flushed with synthetic Site 300 water. The upstream water stream valve was then closed while the downstream water stream valve was kept open. The upper chamber was next filled with solvent from the upstream solvent tank, and the chamber was flushed with solvent with the downstream solvent stream valve held open. The downstream solvent stream valve was then closed. At this point, if there are no leaks as the clay-cell wall interface, there would be no 
flow of either solvent or water because flow can take place only through the nearly impermeable clay layer within the cell. In the experiments we performed, there was essentially no flow through the crack propagation cell until the cracks broke through the clay layer. The downstream solvent stream valve was opened periodically to acquire ethanol-water fraction and tracer concentration readings in the upper chamber. Upon ethanol breakthrough across the clay layer, the flow rate increased so high that it could be sustained only for few minutes before it exceeded the limited storage capacity of the water stream effluent collection tank placed on the mass balance. At this time, the experiment was terminated by closing the upstream solvent stream valve, and the downstream water stream valve. The confining air pressure and the pinching air pressure lines were then shut off to maintain the stress state intact, and the crack propagation cell was prepared for relocation to the X-ray imaging station by disconnecting all fluid stream and air pressure lines.

\section{X-Ray Crack Imaging}

The crack imaging procedure was to image the clay layer at the beginning of the experiment before the upstream chamber was filled with the solvent, and periodically thereafter while the ethanol solvent was invading the clay through the newly created extending cracks. A series of $3 \mathrm{D}$ difference images can then be created by subtracting the initial image from the subsequent images to delineate the changes in the fabric more clearly. To acquire these images, the crack propagation cell was placed in front of the X-ray source on a rotating table, as indicated in Figure 8, and the X-rays passing through the clay layer and received at the detector array on the opposite side were recorded while the cell was rotated and translated vertically through the X-ray beam. From this suite of raw X-ray transmission images, a full 3D image of the clay layer at each time was built up using computer-aided tomographic image construction algorithms that are based on the equations that govern X-ray transmission, absorption and scattering of X-rays in materials. In the results presented in this report it was not necessary to produce difference images because the cracks were clearly visible in the original tomographic images.

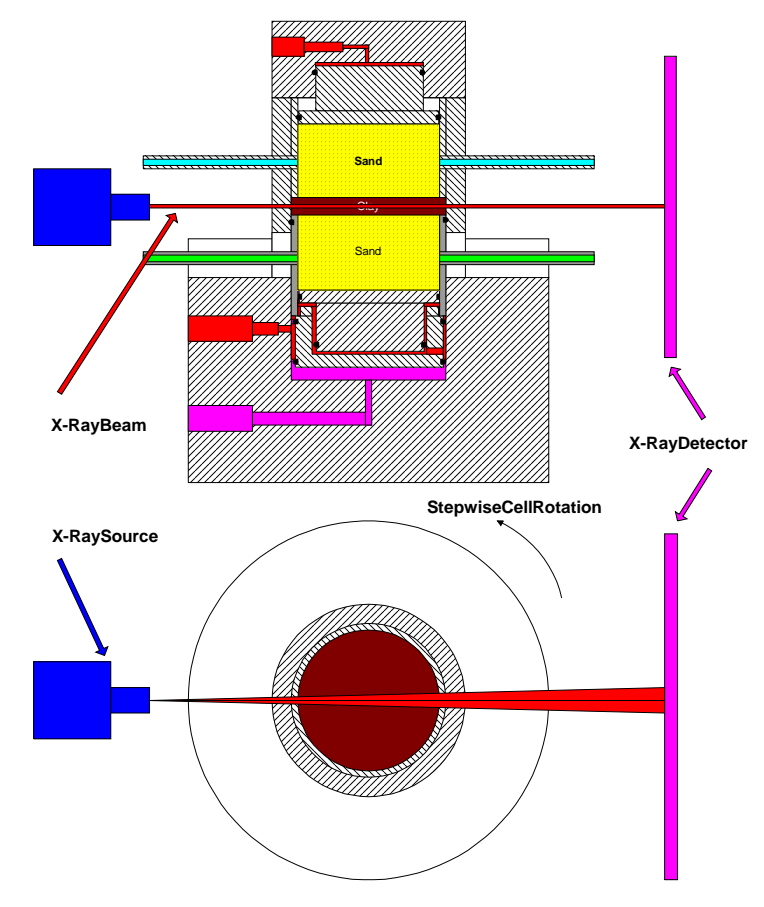

Figure 8. Experimental Setup for Crack Imaging by X-ray Tomography

Although previous applications of $\mathrm{X}$-ray absorption imaging have been mainly for rocks with porosities of $\sim 20 \%$ [20], recent advances in detectors, X-ray sources, and image processing software 
have extended the utility of X-ray observations to lower porosity rocks (3-11\%) containing fluids, including fractured volcanic tuffs [21], with a spatial resolution of $100 \mu \mathrm{m}$ at a minimum detectable contrast difference of $0.5 \%$. We used the PCAT computed tomography and digital radiography system belonging to LLNL's Manufacturing and Materials Evaluation Division (MMED). This 20-450kV system with a high resolution $250 \times 250 \mathrm{~mm}$ area array scintillation X-ray detector proved to be capable of resolving $40 \mu \mathrm{m}$ wide features in the clay. We used MMED's ImgRec X-ray tomography software [23] to reconstruct a 3D data volume from the measured raw X-ray radiographs. This software also makes it possible to view the 3D data on any specified cross-sectional plane, and to measure the dimensions of individual features, such as crack lengths and widths, from the tomographic images. Furthermore, using this and other utility software, we have produced movies to compactly present all of the crack data in the images as the circular clay disk is scanned in slices normal and parallel to its axis.

\section{Experimental Materials: Synthetic Site 300 Water}

A stock solution of synthetic Site 300 water was prepared for use in all shrinkage coefficient and crack propagation experiments. The chemical composition of the water used for the experiment was designed to match the major element chemistry and $\mathrm{pH}$ of groundwater at Site 300 . The Site 300 water composition was supplied by the Environmental Restoration Division of LLNL. Major element analysis and $\mathrm{pH}$ of groundwater from Site 300 well W-815-03 (8-May-91) were used as input to the geochemical modeling code REACT [22]. The REACT code outputs a fluid composition that is both electrically neutral (by adjusting the chloride concentration), and is not supersaturated with respect to easily precipitated phases such as calcite. The output from React was then input to a spreadsheet that computes the masses of reagent grade chemicals necessary to formulate the solution. The measured $\mathrm{pH}$ of the prepared solution of synthetic Site 300 water was 8.1 .

Table 1. Chemicals Required for Preparation of Synthetic Site 300 Water

\begin{tabular}{|c|c|}
\hline Chemical & Mass gm \\
\hline $\mathrm{H} 2 \mathrm{O}$ (Deionized) & 10,000 \\
$\mathrm{Na} 2 \mathrm{SO} 4$ & 1.9680 \\
$\mathrm{KCl}$ & 0.1524 \\
$\mathrm{NaCl}$ & 2.7910 \\
$\mathrm{MgCl} 2$ & 0.5977 \\
$\mathrm{CaCl} 2$ & 0.3990 \\
$\mathrm{NaHCO} 3$ & 1.6810 \\
$\mathrm{MgSO} 4$ & 0.0856 \\
\hline
\end{tabular}

\section{Experimental Materials: Solvent and Water Solutions With Conservative Tracers}

In order to track and interpret the movement of the ethanol and water through the bentonite clay disk, it was decided to tag the ethanol in the supply tank and the bentonite clay were with two noninterfering non-sorbing "conservative" tracers. Non-interfering tracers do not influence the readings of the other tracers when concentrations are measured using ion-selective electrodes. Accordingly, bromide $(\mathrm{NaBr})$ was selected as the ethanol tracer, and perchlorate $\left(\mathrm{NaClO}_{4}\right)$ as the clay tracer. However, both $\mathrm{NaBr}$ and $\mathrm{NaClO}_{4}$ need water to be soluble and are insoluble in pure ethanol. For this reason, the ethanol tracer was not used for experiments conducted with $100 \%$ ethanol. To tag the clay, a solution containing $1,000 \mathrm{ppm}$ of sodium perchlorate (i.e. $\mathrm{NaClO}_{4}$ ) in synthetic Site 300 water was prepared. This solution was mixed with the bentonite clay to form a thick clay paste that was used to mold the clay disks used in the shrinkage coefficient measurement, and crack propagation experiments. The responses of both of these 
ion-selective electrodes required a significant calibration effort because they were strongly affected by the ethanol-water fraction in liquid stream (see Electrode Calibration section).

\section{Experimental Materials: Bentonite Clay}

The bentonite clay used in these experiments was a calcium bentonite, with the trademark name Pelbon, that is manufactured by the American Colloid Company of 1500 W. Shure Drive, Arlington Heights, Illinois 6004-7803. This product, supplied as a grey 150 mesh powder, is a hydrous aluminum silicate composed primarily of montmorillonite, with minor amounts of quartz, feldspar and mica as impurities. The chemical and physical properties of the Pelbon clay, provided by the manufacturer, are given in Table 2.

Preliminary molding experiments and permeability experiments with this clay showed that a clay paste having $39.76 \%$ water and $60.24 \%$ clay powder by weight had a consistency suitable for preparing the clay disks for the shrinkage and crack propagation experiments. Preliminary permeability experiments performed with water showed that the flow rate through a $1 \mathrm{~cm}$ thick clay layer prepared with a thick clay paste with this water content was below the flow rate measurement accuracy in our crack propagation tests.

Table 2. Physicochemical Properties of PELBON Calcium Bentonite Clay.

\begin{tabular}{|c|c|c|}
\hline Property & \multicolumn{2}{|c|}{ Value } \\
\hline Bulk density & \multicolumn{2}{|c|}{$0.801-0.961 \mathrm{~g} / \mathrm{cm}^{3}\left(50-60 \mathrm{lb} / \mathrm{ft}^{3}\right)$} \\
\hline Dry particle size & \multicolumn{2}{|c|}{40 Minimum passing 200 Mesh (74 micron) } \\
\hline $\mathrm{pH}$ & \multicolumn{2}{|c|}{5.0 to $9.0 @ 5 \%$ solids } \\
\hline Moisture & \multicolumn{2}{|c|}{ Maximum 15\% (as shipped) } \\
\hline $\begin{array}{l}\text { Exchangeable cation } \\
\text { concentration }\end{array}$ & $\begin{array}{ll}\mathrm{Ca} & 60 \\
\mathrm{Na} & \\
\mathrm{Mg} & 5- \\
\mathrm{K} & \end{array}$ & $\begin{array}{l}0 \mathrm{meq} / 100 \mathrm{~g} \\
3 \mathrm{meq} / 100 \mathrm{~g} \\
5 \mathrm{meq} / 100 \mathrm{~g} \\
4 \mathrm{meq} / 100 \mathrm{~g}\end{array}$ \\
\hline $\begin{array}{l}\text { Composition } \\
\text { (moisture free) }\end{array}$ & $\begin{array}{l}\mathrm{SiO}_{2} \\
\mathrm{Al}_{2} \mathrm{O}_{3} \\
\mathrm{Fe}_{2} \mathrm{O} \\
\mathrm{MgO} \\
\mathrm{CaO} \\
\mathrm{Na}_{2} \mathrm{O} \\
\mathrm{K}_{2} \mathrm{O} \\
\mathrm{LOI}\end{array}$ & $\begin{array}{l}60.5 \% \\
18.2 \% \\
5.25 \% \\
3.26 \% \\
3.14 \% \\
0.20 \% \\
0.14 \% \\
4.85 \%\end{array}$ \\
\hline
\end{tabular}




\section{Instrument Calibrations: Ion-Selective Electrodes}

All solvent and water stream electrodes were calibrated using standard ethanol-synthetic Site 300 water solutions, with and without the presence of the $\mathrm{NaBr}$ and $\mathrm{NaClO}_{4}$ tracer species.

The calibration curves of the ion-selective electrodes for the bromide and perchlorate concentrations, given in Figures 9, 10, 11 and 12, depend strongly on the ethanol fraction in the solventwater solution. Therefore, to determine the concentration of a tracer species in a solvent-water solution, it is necessary to interpolate between the ion-selective electrode output and the ethanol fraction using a two variable interpolation procedure.

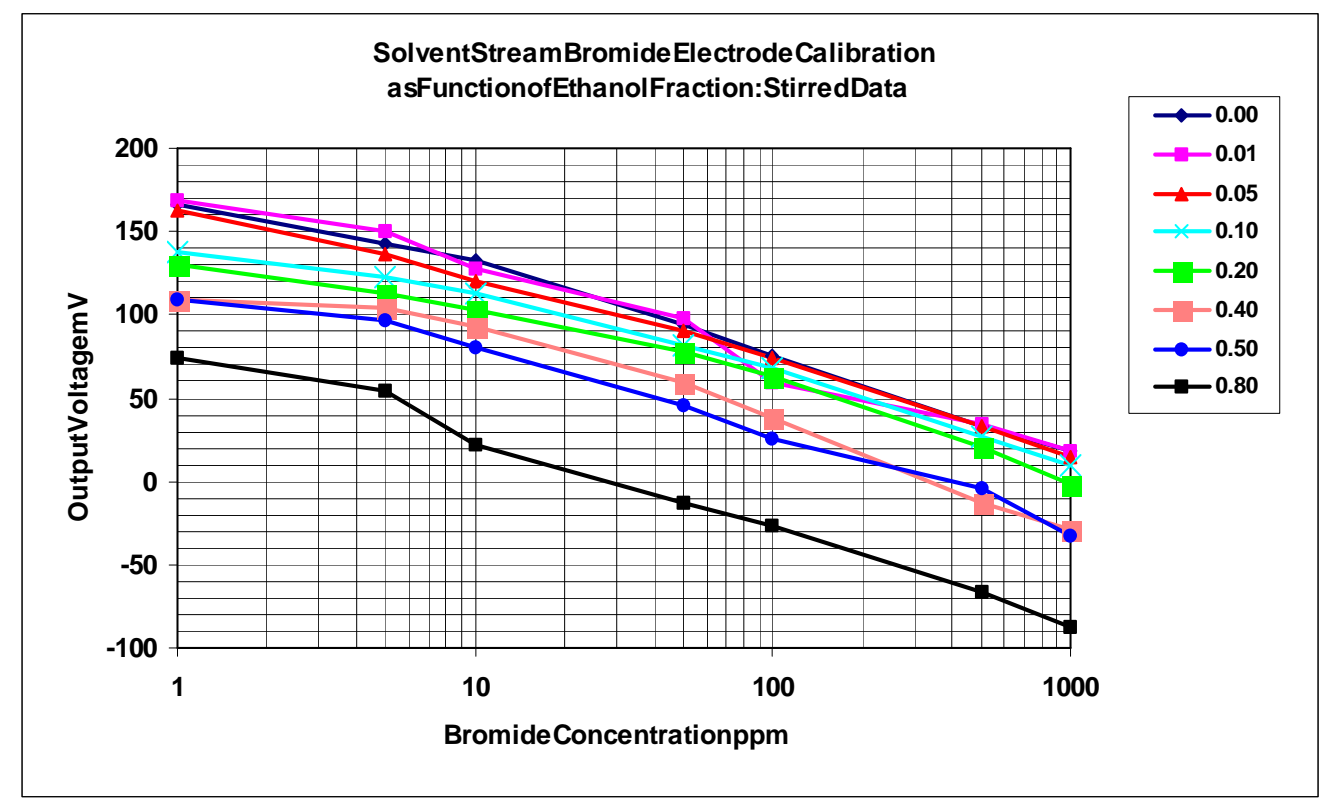

Figure 9. Solvent Stream Bromide Electrode Output as a Function of Bromide Concentration and Ethanol Fraction (See Legend). 


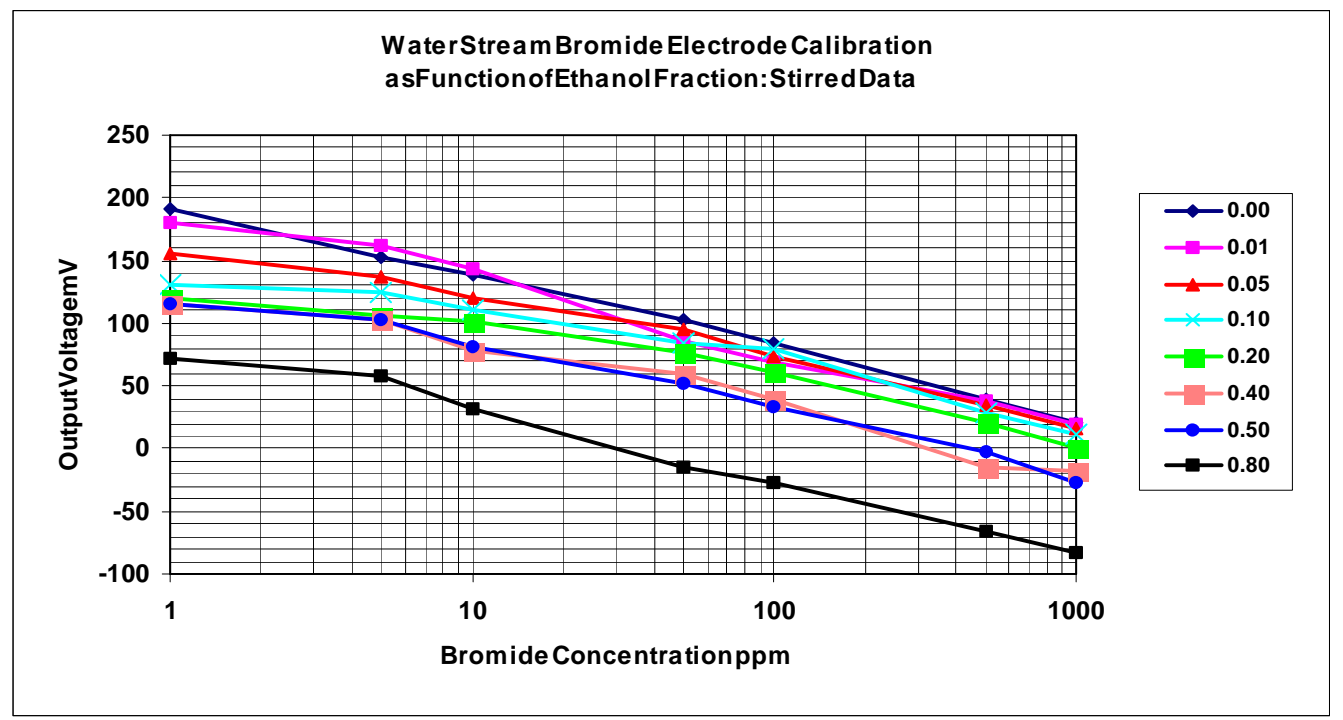

Figure 10. Water Stream Bromide Electrode Output as a Function of Bromide Concentration and Ethanol Fraction (See Legend)



Figure 11. Solvent Stream Perchlorate Electrode Output as a Function of Perchlorate Concentration and Ethanol Fraction (See Legend) 


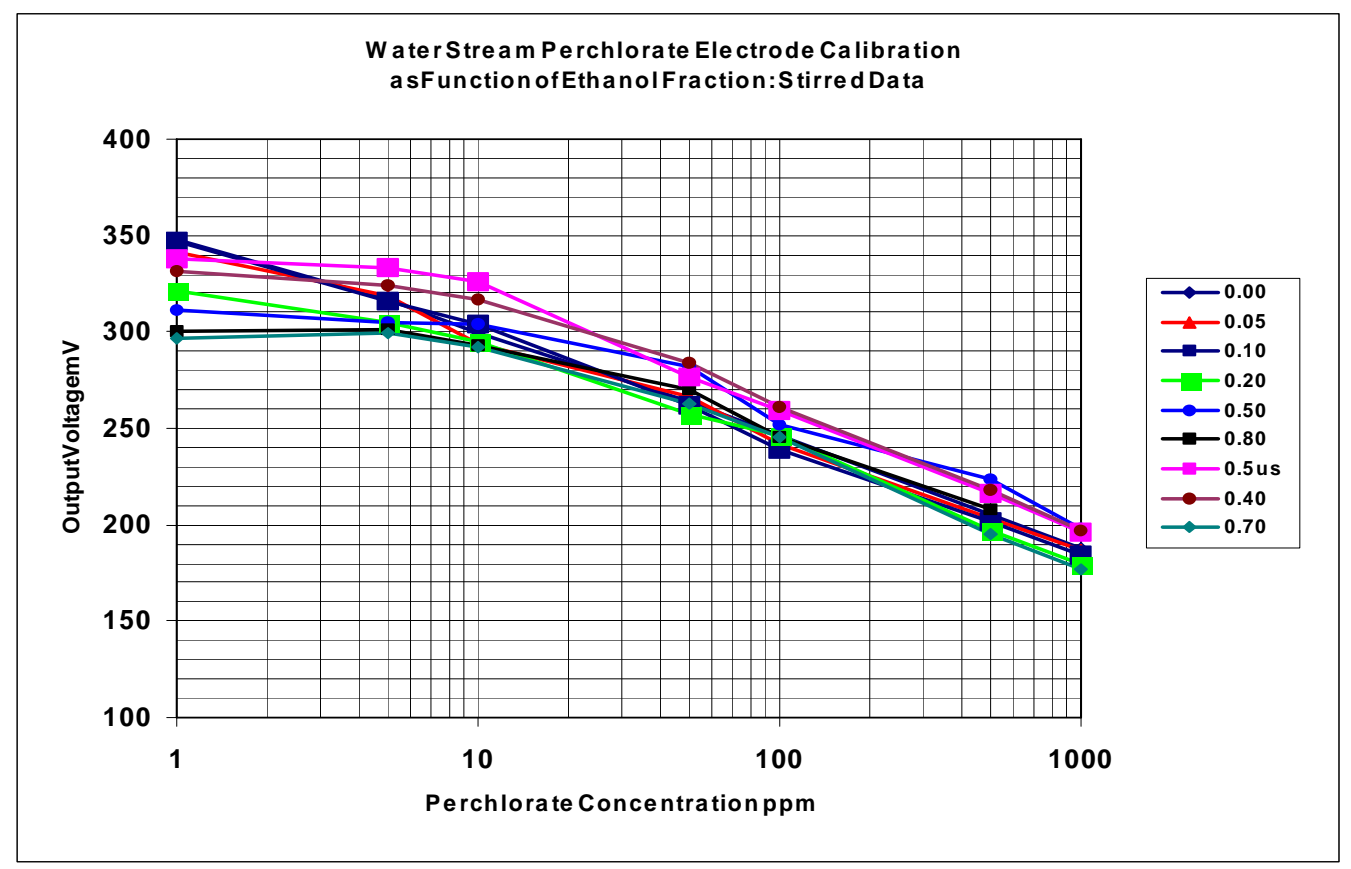

Figure 12. Water Stream Perchlorate Electrode Output as a Function of Perchlorate Concentration and Ethanol Fraction (See Legend)

\section{Instrument Calibrations: Electrical Conductivity Electrode}

The electrical conductivity of the pore water within the clay is an important parameter for assessing the state of swelling/shrinkage of the clay. Therefore, the electrical conductivity was measured in the water stream exiting the flow cell. The electrical output of the electrical conductivity probe calibrated using standard conductivity solutions is given in Figure 13. To prevent polarization at the platinum electrodes of the probe, a $1,100 \mathrm{~Hz}$ AC supply voltage of sinusoidal waveform was used instead of a DC voltage supply. The AC voltage was supplied by a custom built signal generator with very low impedance output. The conductivity probe was connected in series with a known resistance to form a voltage divider circuit and the voltage drop across the probe was measured. As shown in Figures 14 and 15, the electrical conductivity of the ethanol-synthetic Site 300 water-tracer solution measured by the probe is a function of both the ethanol fraction and the tracer species concentrations.

It was anticipated that chemical reactions between the clay and the pore fluid could lead to leaching of chemical species from the clay and alteration of the ionic strength of the synthetic Site 300 water. To assess the extent of these interactions, the electrical conductivity of synthetic Site 300 water, and of synthetic Site 300 water used to leach clay by three different methods were measured. The three leached solutions were prepared by mixing $25 \mathrm{~g}$ of PELBON calcium bentonite clay with $100 \mathrm{~g}$ of synthetic Site 300 water and 1. stirring for 5 minutes, 2. stirring and heating at $80 \mathrm{C}$ for 5 minutes, and 3 . stirring for 5 minutes and letting it sit in contact with the clay for 24 hours, and then filtering out the leaching liquid. The measured electrical conductivities of these four different solutions are shown in Figure 16 and are given in Table 4. These results show that the effects of leaching on the electrical conductivity and on the ionic strength are likely to be small. Therefore, it was decided to neglect the effects of clay leaching. 
Table 3. Electrical Conductivity of Synthetic Site 300 Water in Contact with PELBON Clay.

\begin{tabular}{|l|c|c|}
\hline \multicolumn{1}{|c|}{ Solution } & Conductivity & Ratio \\
\hline Synthetic Site 300 water & 1251.47 & 1.0000 \\
5 min Stirred Leaching & 1360.79 & 1.0813 \\
5 min Stirred \& Heated Leaching & 1422.27 & 1.1302 \\
5 min Stirring \& 24 hr Leaching at Rest & 1402.49 & 1.1144 \\
\hline
\end{tabular}

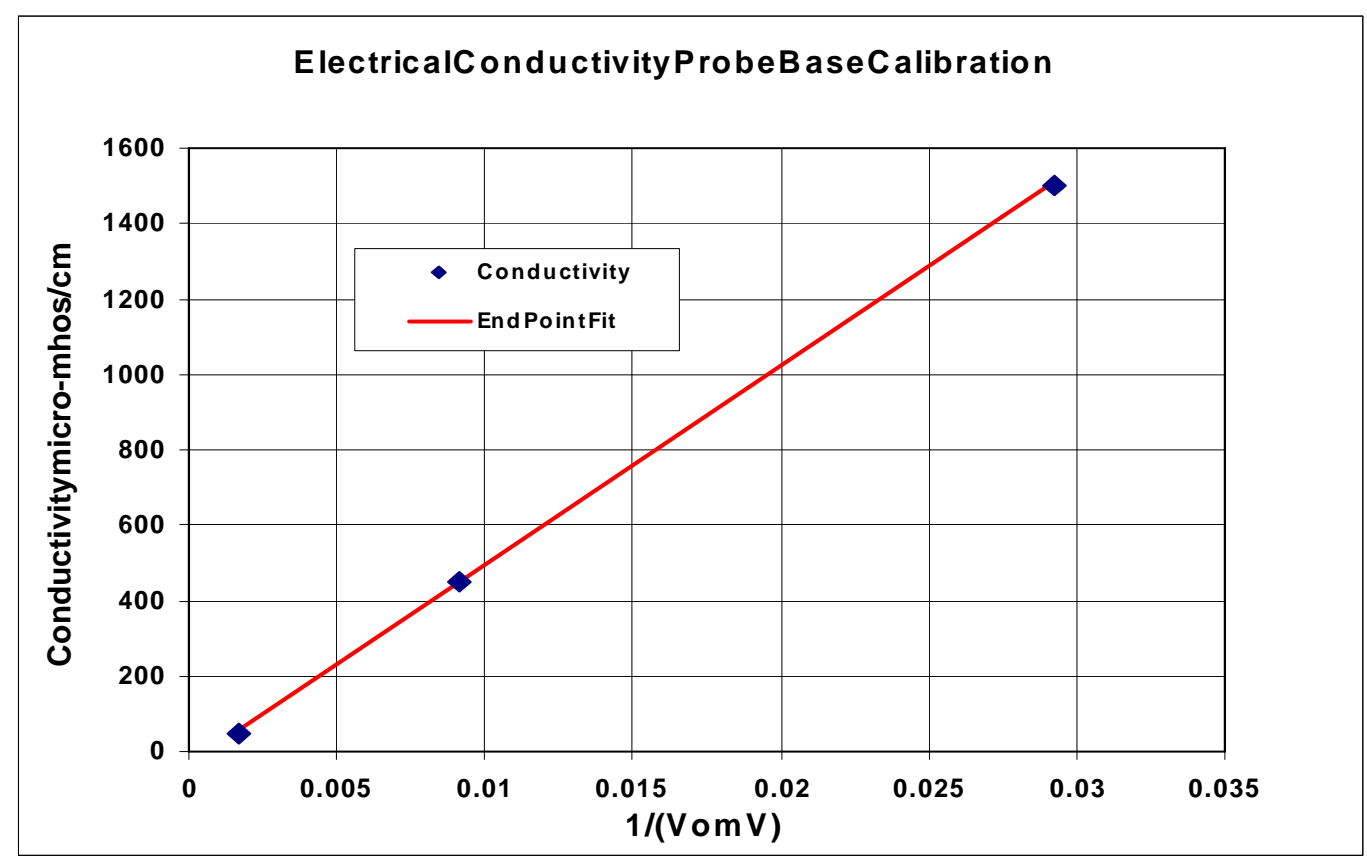

Figure 13. Electrical Conductivity Probe Base Calibration Using KCI Standard Conductivity Solutions 




Figure 14. Electrical Conductivity Probe Output as Function of Bromide Concentration and Ethanol Fraction (See Legend).

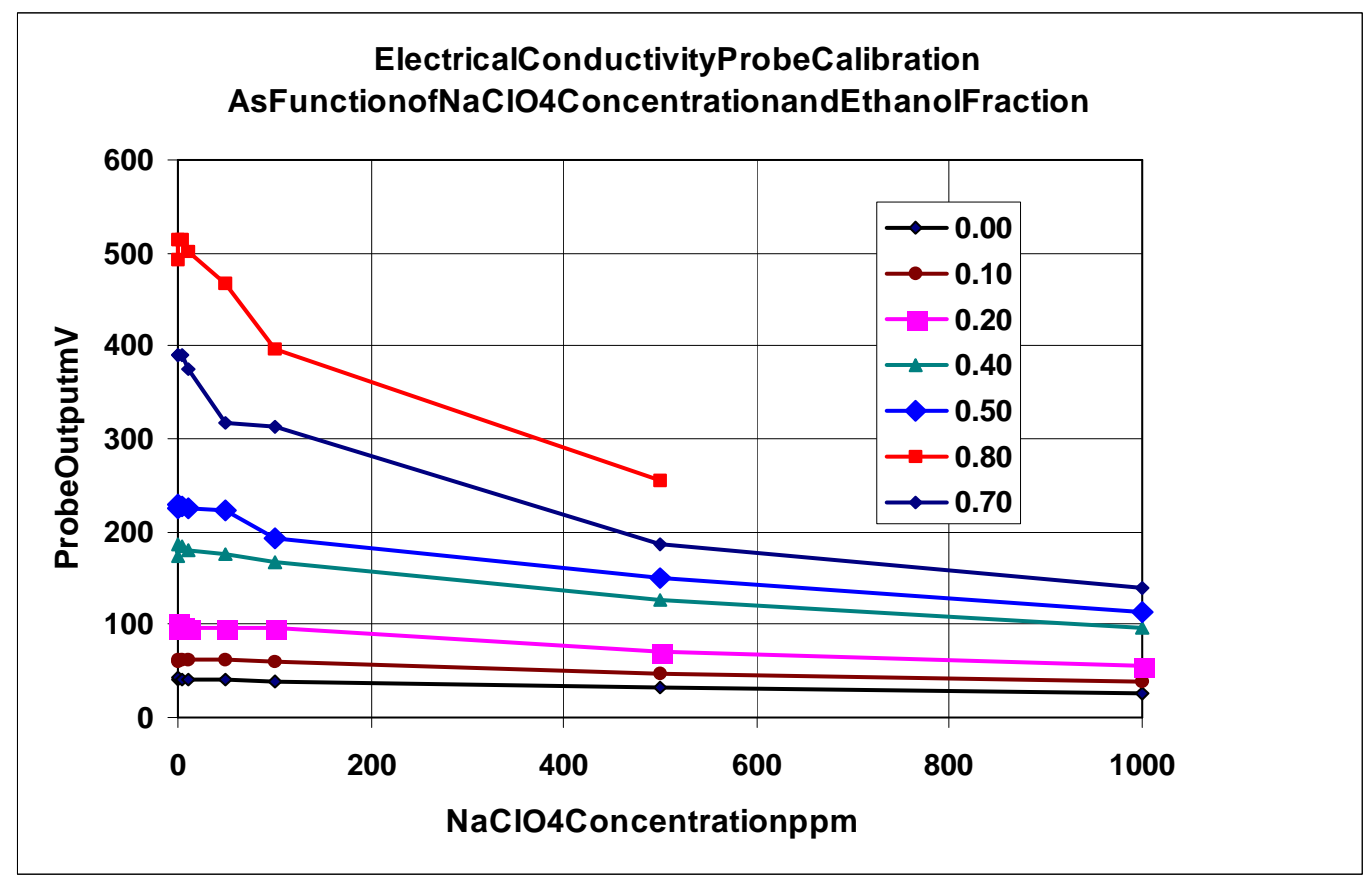

Figure 15. Electrical Conductivity Probe Output as Function of Perchlorate Concentration and Ethanol Fraction (See Legend). 


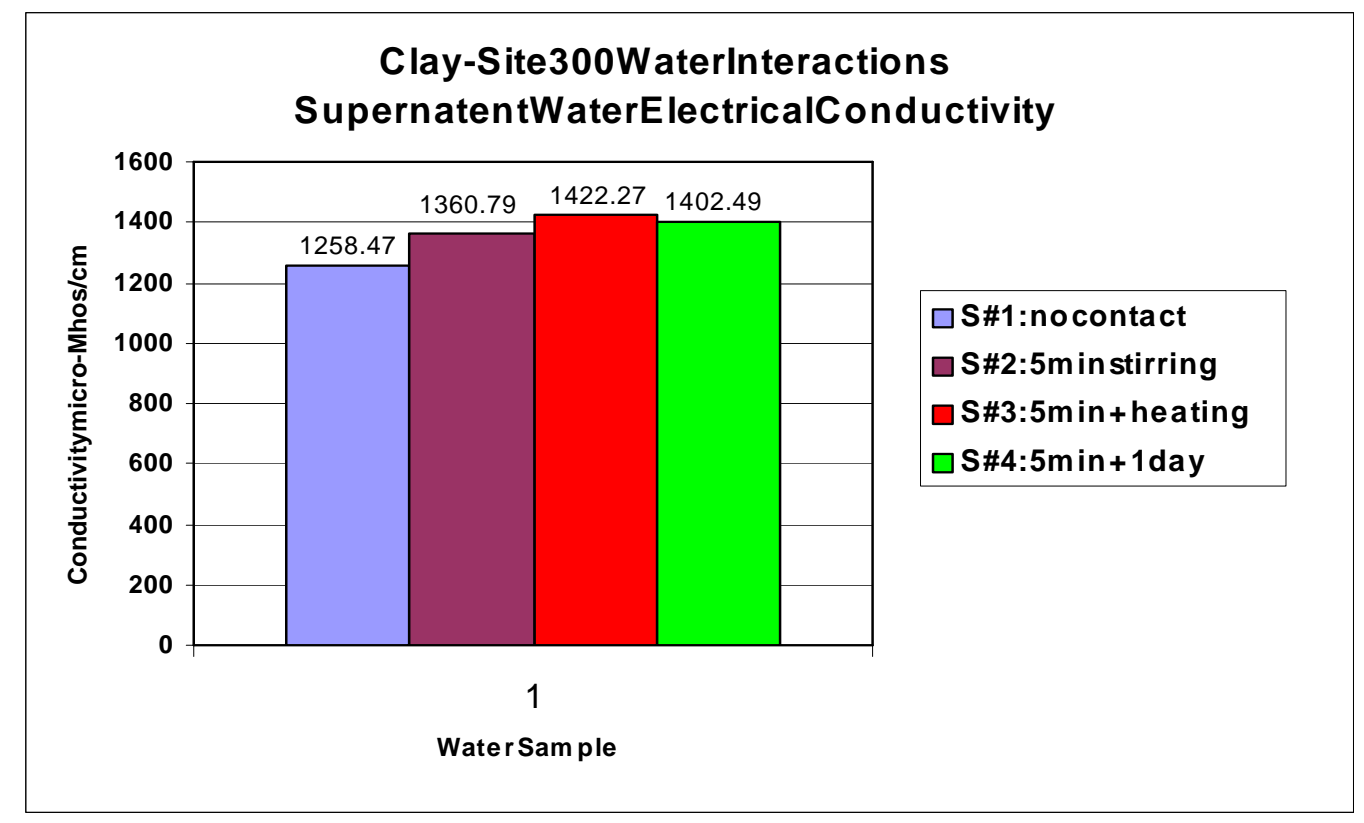

Figure 16. Electrical Conductivity of Site 300 Water in Contact with PELBON Calcium Bentonite Clay

\section{Instrument Calibrations: Ethanol Fraction and Temperature Measurement Sensors}

The capacitance electrodes for measuring the ethanol fraction in the liquid streams were calibrated in two ways. First method was by determining the capacitance electrode parameters. The total capacitance measured by the capacitance sensor can be modeled as that due to the capacitance of the fluid column that occupies the annular space within the capacitor, connected in series with the fixed capacitance due to the electrical insulation that insulates the electrodes from the conductive liquid. The first of these two capacitances is proportional to the dielectric coefficient of the fluid. The constant of proportionality for the fluid capacitance, and the insulation capacitance represent two unknown constants that can be determined by measuring the capacitance of two liquids of known, but different, dielectric coefficients. The second method is to calibrate the overall sensor capacitance directly against the ethanol fraction of a series of ethanol-synthetic Site 300 water solutions of known ethanol mass fractions. The calibration curve obtained by the latter method is shown in Figure 17.

Finally, the temperature probe installed in the solvent stream electrode cluster was calibrated against a mercury-in-glass thermometer as shown in Figure 18. 


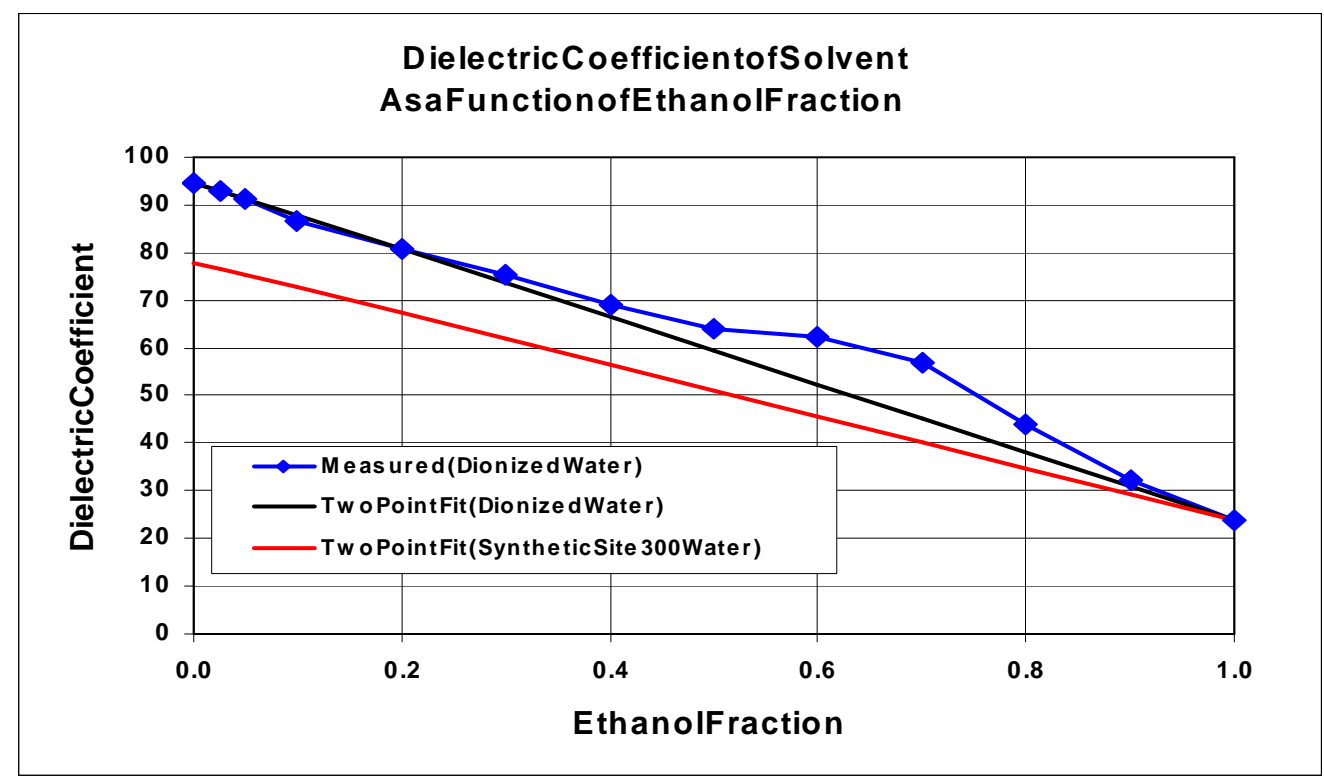

Figure 17. Variation of the Dielectric Coefficient of Ethanol-Water Solution with Ethanol Fraction

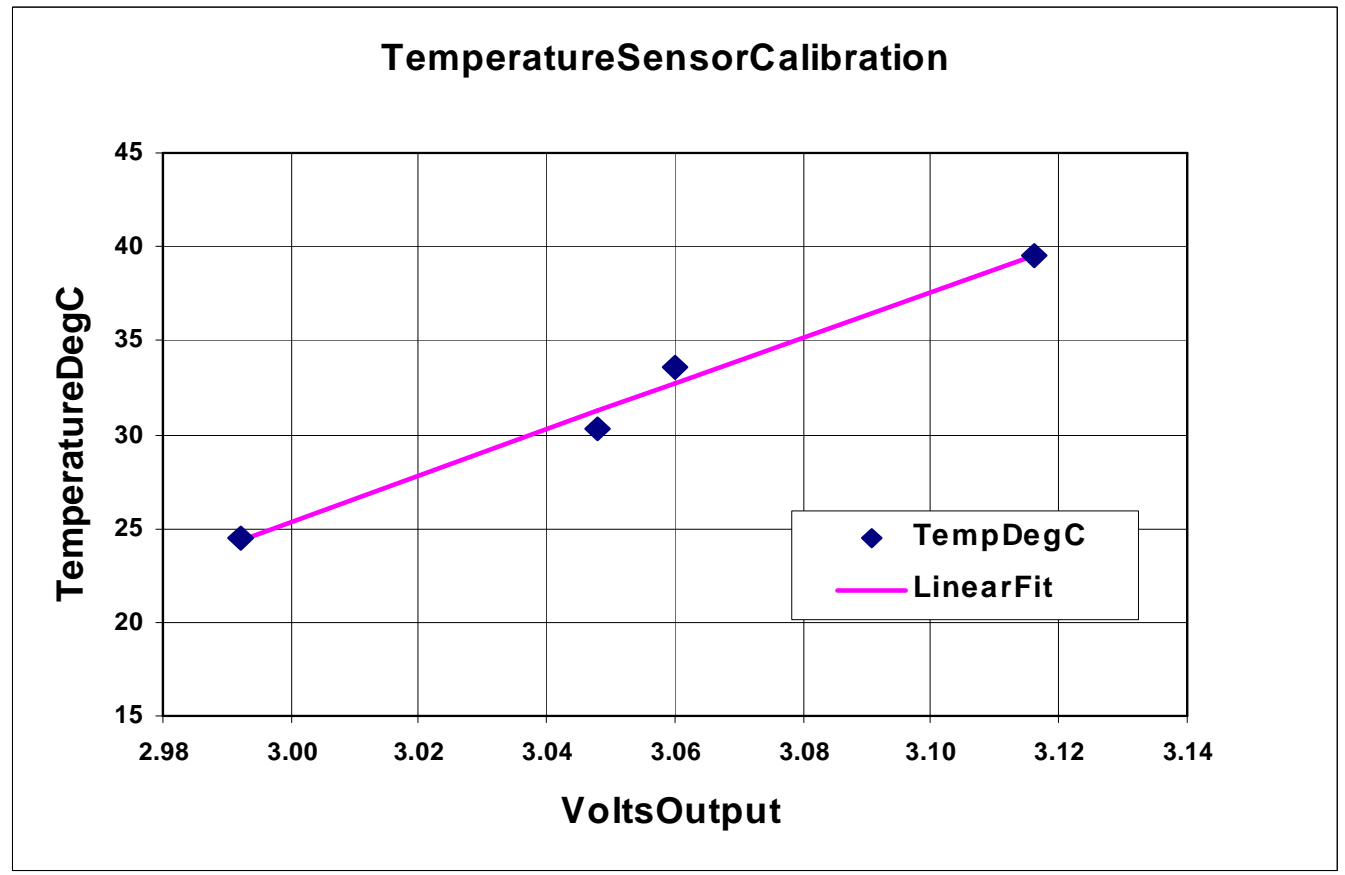

Figure 18. Temperature Probe Output Voltage Versus Temperature 


\section{RESULTS}

\section{Crack Propagation Experiment}

The crack propagation experiment was initiated with $100 \%$ ethanol as the solvent upon completion of all of the instrument calibrations presented in Section 4. A confining pressure of 15 psi was first applied to the upper and lower loading pistons, followed by a pressure of $17 \mathrm{psi}$, (for an estimated normal pinching stress of $25.5 \mathrm{psi}$ ) imposed on the pinch loading piston to seal the clay-wall interface. A constant pressure difference of 0.0723 psi ( 2 in of water) was maintained between the solvent and water sand chambers. The downstream water stream ethanol fraction, the bromide and perchlorate tracer concentrations, the electrical conductivity, the solvent temperature and the cumulative effluent mass read by the mass balance were continuously measured in anticipation of solvent breakthrough across the $1 \mathrm{~cm}$ thick clay layer.

This experiment was started on October 31, 2003 and the solvent perfusion was continued for 33 days until December 3, 2003. Our theoretical estimates indicated that although solvent break-through was not evident after 33 days, sufficient time had passed for solvent breakthrough across the clay layer to have occurred. Because the traces of several through-going cracks could be seen through the transparent cell wall, we decided that flow path in the exit line must be blocked by undetected air bubbles and that the pressure head of $0.0723 \mathrm{psi}$ ( 2 in of water) applied across the clay layer was too small to overcome this blockage. To remedy this, we increased the pressure head applied across the clay layer from $0.0723 \mathrm{psi}$ ( 2 in of water) to $0.510 \mathrm{psi}$ (14.125 in of water). This immediately caused solvent to flow across the clay layer at a very high mass flow rate. We concluded that the initial crack breakthrough had actually occurred many days earlier, perhaps within the very first week, but it remained undetected because the applied hydraulic head was too low to over come blockage by the air bubbles. Upon removal of this air block on December 3,2003 , the flow rate increased immediately to a very high level indicating that the throughgoing cracks had already been created.

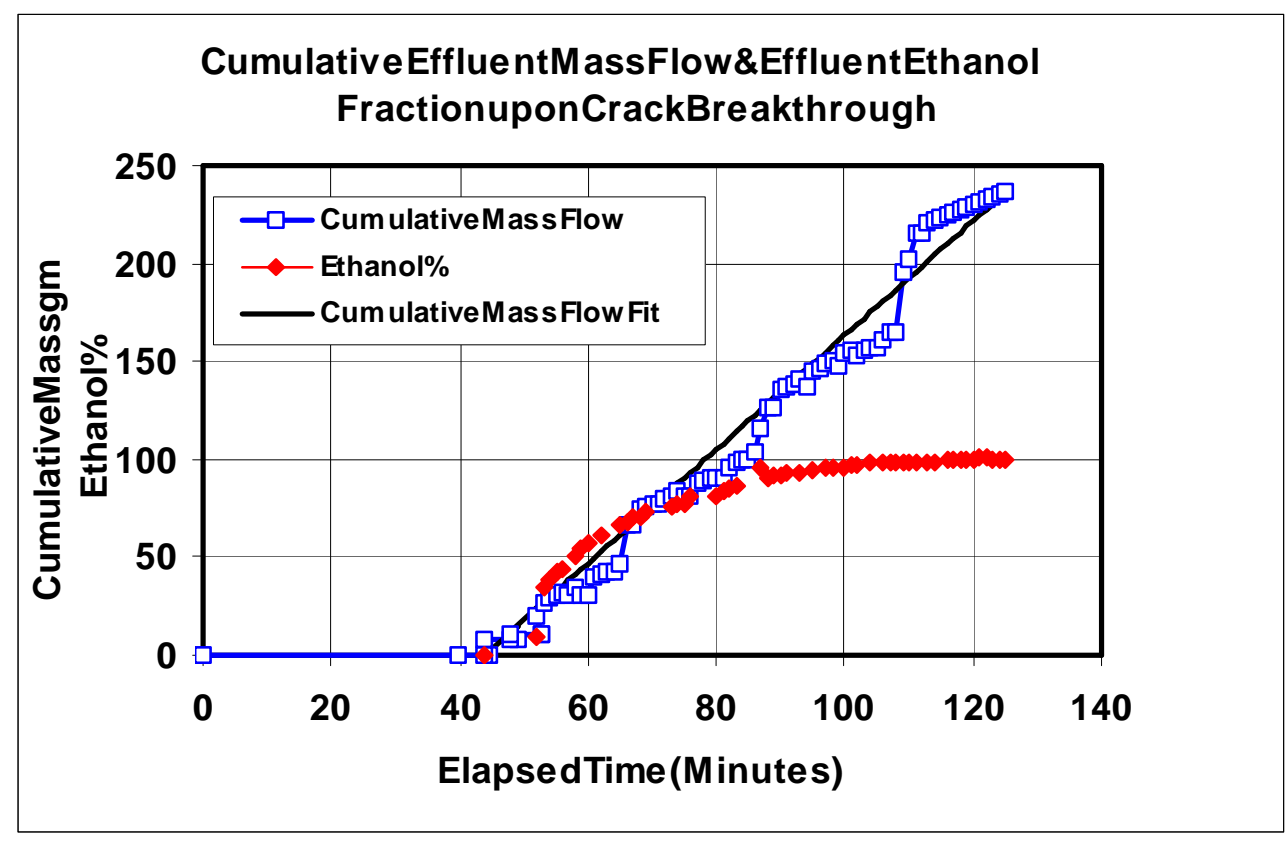

Figure 19. Cumulative Effluent Mass Flow and Effluent Ethanol Fraction upon Crack Breakthrough 
The time history of the cumulative mass flow through the clay layer, and the ethanol-water fraction from $1.15 \mathrm{pm}$ on 12/03/2003 are shown in Figure 18. There was essentially no liquid flow in the water stream and the water stream capacitance sensor measured a value of zero ethanol fraction before we cleared the air bubble blockage. Upon solvent breakthrough 50.02 minutes later, the cumulative mass flow increased rapidly, at an average mass flow rate of $2.875 \mathrm{~g} / \mathrm{min}$ until the experiment was terminated 75.98 minutes after solvent breakthrough. The steps evident in this curve arose from shutting off the downstream water flow to permit offloading liquid from the collection tank placed on the mass balance. During this flow period, the ethanol fraction rose from zero to unity.

\section{Diffusive Transport of Ethanol in Uncracked Bentonite Clay}

In this experiment, until crack breakthough causes the water in the water side chamber to be rapidly displaced by ethanol, the water side boundary is held at $0 \%$ ethanol fraction, while ethanol diffuses into the clay layer from the ethanol side which is held at $100 \%$ ethanol mass fraction. If these boundary conditions on the ethanol fraction are maintained longer than the charactertistic diffusion time $t_{D}$, then the profile of the ethanol fraction within the clay layer will become a straight line between $100 \%$ and $0 \%$ at the two boundaries. If the crack is driven by the ethanol concentration established hroughout the clay layer by this diffusion process, then the crack must stop extending at some distance from the ethanol boundary within the clay because beyond that point the ethanol fraction, and the resulting shrinkage, is too small to crack the clay further. However, this did not happen in this experiment, and the crack continued to extend beyond this point to the water side boundary because, as depicted in Figure 3, the crack carries its own ethanol diffusion front with it and the crack surface is always in contact with the ethanol of high concentration carried along within the crack itself. The central premise of the current study is to demonstrate that crack propagation would not be limited by the speed of diffusion from the external boundary originally exposed to the ethanol.

The characteristic diffusion time $t_{D}$ can be estimated, as shown in Table 4 , from $t_{D}=L^{2} / D_{e c}$ where $L$ is the thickness of the clay disk, and the effective diffusion coefficient $D_{\text {ec }}$ for ethanol in the clay material. The effective diffusion coefficient is calculated from $D_{\text {ec }}=\phi D_{\text {ew }} / \tau$ where $\phi$ and $\tau$ are the porosity and tortuosity, respectively, of the clay and $D_{\text {ew }}$ is the diffusion coefficient of ethanol in bulk water.

Table 4. Time Required for the Ethanol Diffusion Front to Traverse the Clay Layer.

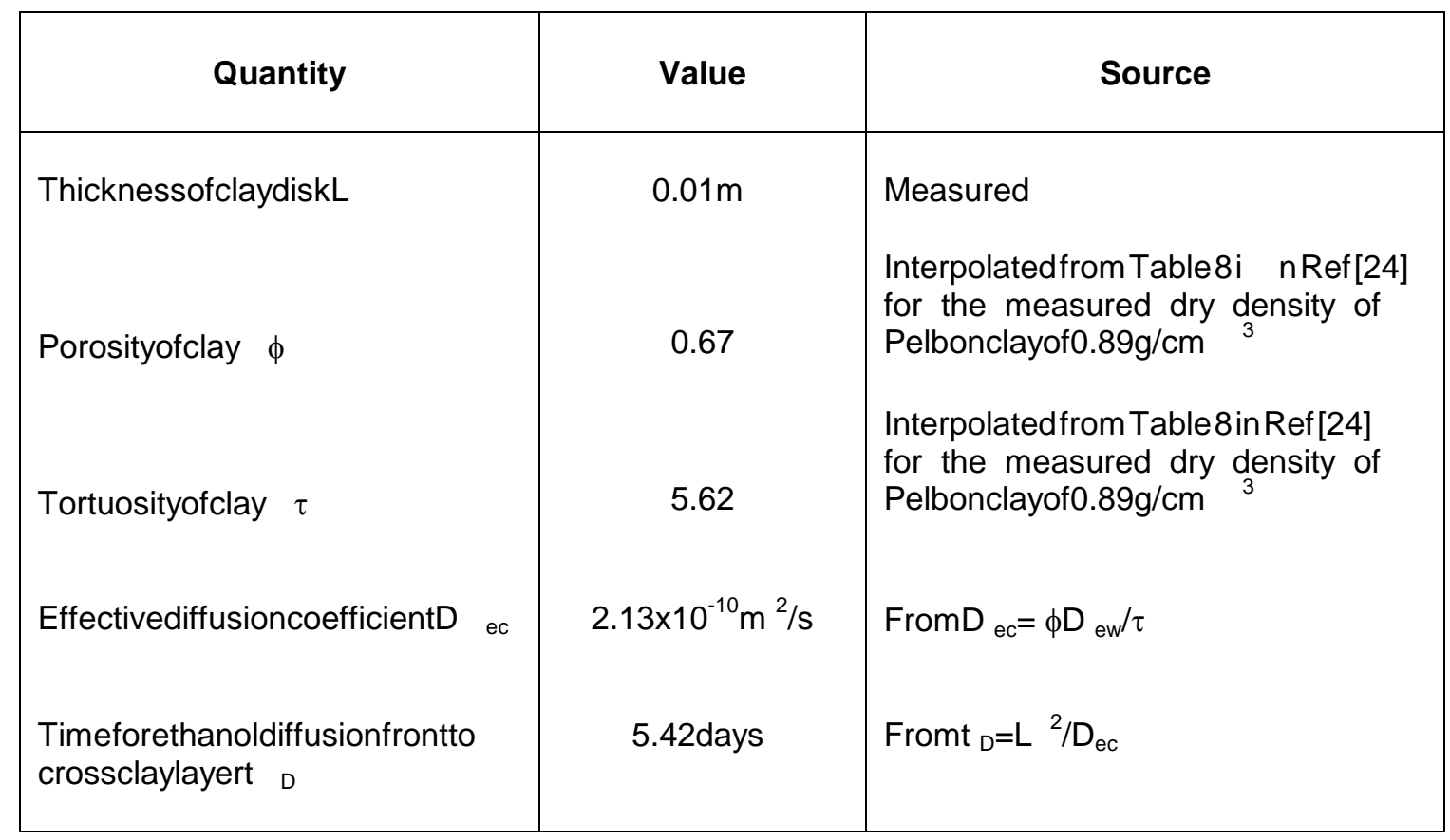




\section{Effective Permeability to Ethanol of Cracked Bentonite Clay Disk}

The effectiveness of cracking the clay layer to gain access to its interior can be assessed, as shown in Table 5 , by comparing the effective permeability of the cracked clay disk to permeabilities published in the literature for typical bentonite clays. The permeability ratio between the measured effective permeability of the cracked clay, and the permeability typical of an unaltered bentonite clay, is seen to be extremely large

Table 5. Increase in Effective Permeability due to Shrinkage Induced Clay Cracking.

\begin{tabular}{|c|c|c|}
\hline Quantity & Value & Source \\
\hline Thickness of clay disk $L_{c}$ & $0.01 \mathrm{~m}$ & Measured. \\
\hline $\begin{array}{l}\text { Pressure difference across clay } \\
\text { layer } \Delta \mathrm{h}\end{array}$ & 14.125 in. water & Measured. \\
\hline $\begin{array}{l}\text { Average D'Arcy flow velocity } \\
\text { through cracked flow disk } V_{D}\end{array}$ & $9.68 \mathrm{~cm} / \mathrm{s}$ & $\begin{array}{l}\text { From the measured average mass } \\
\text { flow rate of } 2.875 \mathrm{~g} / \mathrm{min} \text { and the } \\
\text { clay disk diameter of } 1.875 \mathrm{in} \text {. }\end{array}$ \\
\hline $\begin{array}{l}\text { Effective permeability of cracked } \\
\text { clay disk } k_{\text {eff }}\end{array}$ & $2.45 \times 10^{-4} \mathrm{~cm}^{2}$ & From $k_{\text {eff }}=V_{D}\left(\mu_{\mathrm{e}} / \rho_{\mathrm{w}} \mathrm{g}\right)\left(\mathrm{L}_{\mathrm{c}} / \Delta \mathrm{h}\right)$ \\
\hline $\begin{array}{l}\text { Published bentonite clay } \\
\text { permeability range } \mathrm{k}\end{array}$ & $1 \times 10^{-16}-1 \times 10^{-13} \mathrm{~cm}^{2}$ & From Table 7 in Ref [25]. \\
\hline $\begin{array}{l}\text { Permeability ratio } k_{\text {eff }} / k \text { between } \\
\text { cracked and uncracked clay }\end{array}$ & $2.45 \times 10^{9}-2.45 \times 10^{12}$ & \\
\hline $\begin{array}{l}\text { Estimated total length of visible } \\
\text { cracks (rough estimate) } L_{f}\end{array}$ & $17.64 \mathrm{~cm}$ & $\begin{array}{l}\text { Measured from Cross-Section } 390 \\
\text { of Fig. } 21\end{array}$ \\
\hline $\begin{array}{l}\text { Estimated average crack width w } \\
\text { (rough estimate) }\end{array}$ & $127 \mu \mathrm{m}$ & $\begin{array}{l}\text { Measured from Cross-Section } 390 \\
\text { of Fig. } 21 \text { using ImgRec software }\end{array}$ \\
\hline $\begin{array}{l}\text { Effective permeability of cracked } \\
\text { clay from average crack width }\end{array}$ & $1.90 \times 10^{-7} \mathrm{~cm}^{2}$ & $\begin{array}{l}\text { Calculated from: } \\
\mathrm{k}_{\text {eff }}=(4 / \pi)\left(\mathrm{w}^{2} / 12\right)\left(\mathrm{L}_{f} / \mathrm{D}\right)(\mathrm{W} / \mathrm{D})\end{array}$ \\
\hline $\begin{array}{l}\text { Effective permeability if } 10 \% \text { of } \\
\text { the cracks are } 10 \text { times the } \\
\text { average width }\end{array}$ & $1.81 \times 10^{-5} \mathrm{~cm}^{2}$ & 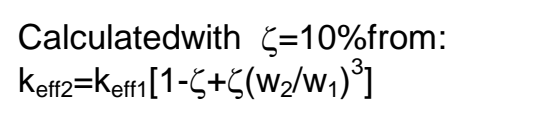 \\
\hline
\end{tabular}


Also, we attempted to obtain a rough estimate the effective permeability of the cracked clay from the measured the total crack length and the average crack width (using ImgRec software) of the readily visible cracks in cross-section \#390 of Figure 21. The results of these calculations are also given in Table 5. The estimated effective permeability calculated in this way was smaller than the measured effective permeability by a factor of 1,436 . This discrepancy can be resolved by more accurately accounting for the much greater flow capacity of cracks of width much greater than the average width, and to a lesser extent the flow capacity of all of the fine cracks that were neglected in the estimate. For example, if $10 \%$ of the total crack length is derived from cracks that are 10 times as wide as the average crack, the discrepancy would close to within a factor of 10 . A few very wide cracks were observed to be present in the cracked clay disk. These estimates and observations support the measured value of effective permeability.

\section{The Crack Images}

Upon termination of the experiment, the fluid and air lines connected to the crack propagation cell were carefully closed off to preserve the states of liquid saturation and mechanical loading, and all lines were disconnected from the cell. The cell was transported to the X-Ray imaging station and the clay layer within it was imaged using the PCAT X-Ray tomography system as previously described. The acquired XRay images were tomographically processed into a 3D volume of image data and cross-sectional slices of the circular clay disk in directions normal and parallel to its axis were prepared.

Upon completion of the imaging process, the cell was dismantled to recover the clay disc. Photographs of the ethanol side surface of the circular cracked disk, and of a prominent, nearly $1 \mathrm{~mm}$ wide, crack intersecting its circular edge are shown in Figure 19.
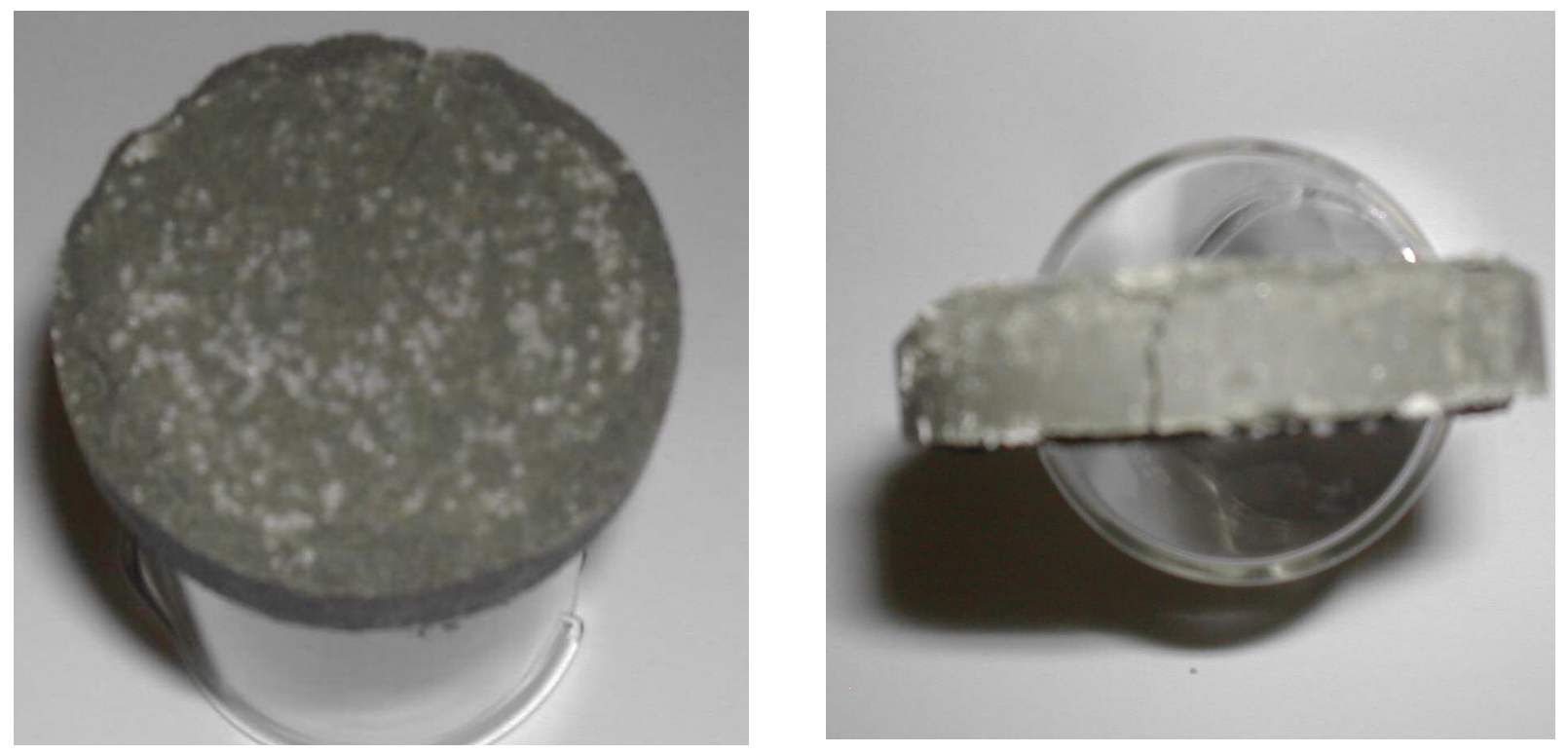

Figure 20: Photographs of Crack Patterns on the Circular Face and the Circular Edge of the Clay Disk

Representative examples of the tomographic cross-sections of the clay disk, taken normal to its axis, are shown in Figure 20. Consecutive cross sections in this sequence were made $48.6 \mu \mathrm{m}$ apart. Cross-section \#190 in Figure 20 shows the quartz sand particles just outside the clay layer on the water side and lying within the sand pack. Cross-section \#220 is 30 cross-sections and $1.458 \mathrm{~mm}$ beyond \#190 into the clay layer, and shows a prominent crack at the bottom of the image and a pattern of thinner cracks elsewhere. These crack patterns persist through the thickness of the clay layer and become more prominent and visible as we move through the clay layer towards the ethanol side of the clay disk. The average crack width of the cracks visible in the images, measured using the ImgRec software, is about $125 \mu \mathrm{m}$, while the widest cracks are more than $1 \mathrm{~mm}$ wide. 

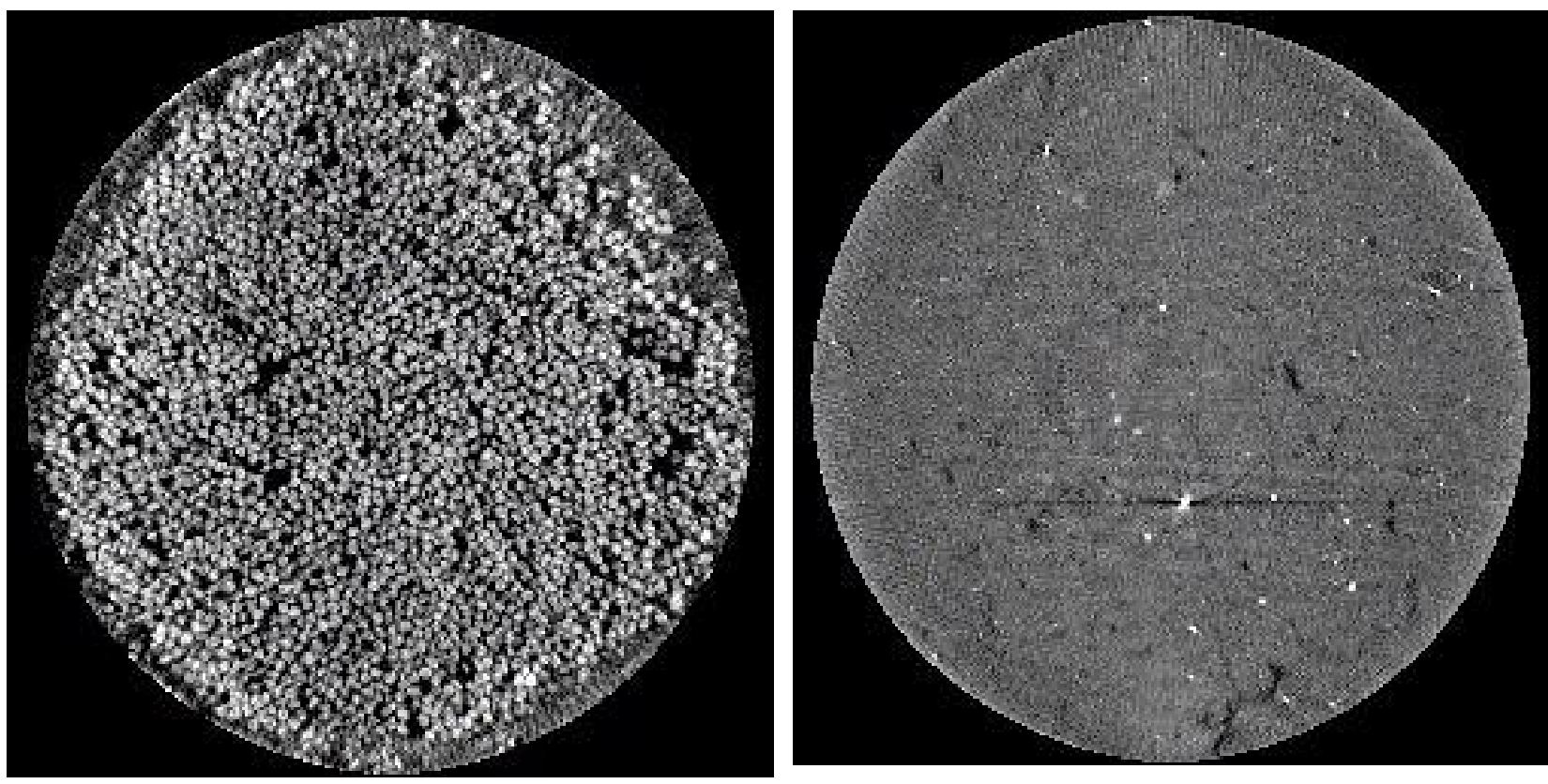

Cross-Section 190

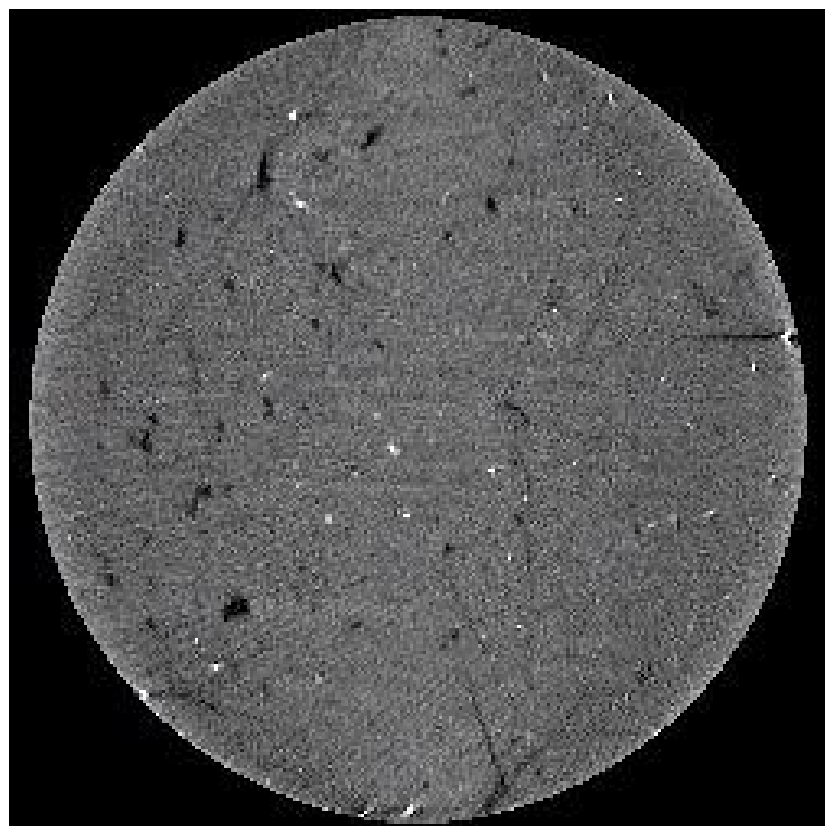

Cross-Section 250
Cross-Section 220

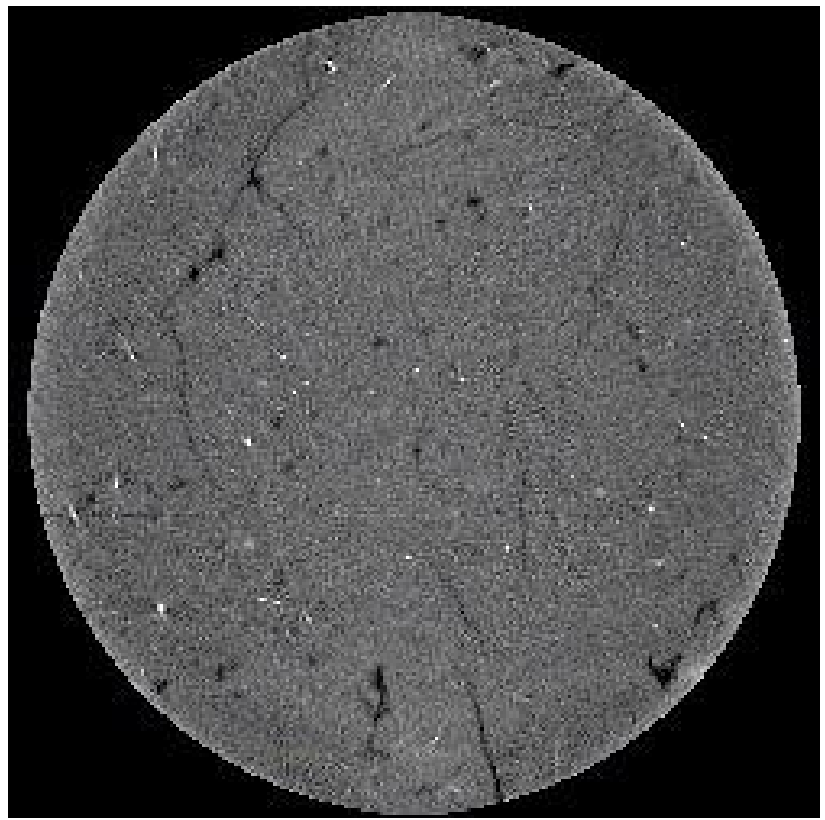

Cross-Section 280

Figure 21: X-Ray Tomography Images of Shrinkage Cracks Created by $100 \%$ Ethanol Perfusion Under 15 psi Confining Stress; Cross-Sections Normal to the Axis of the Clay Disk From the Water Side (200) to the Ethanol Side (390). 

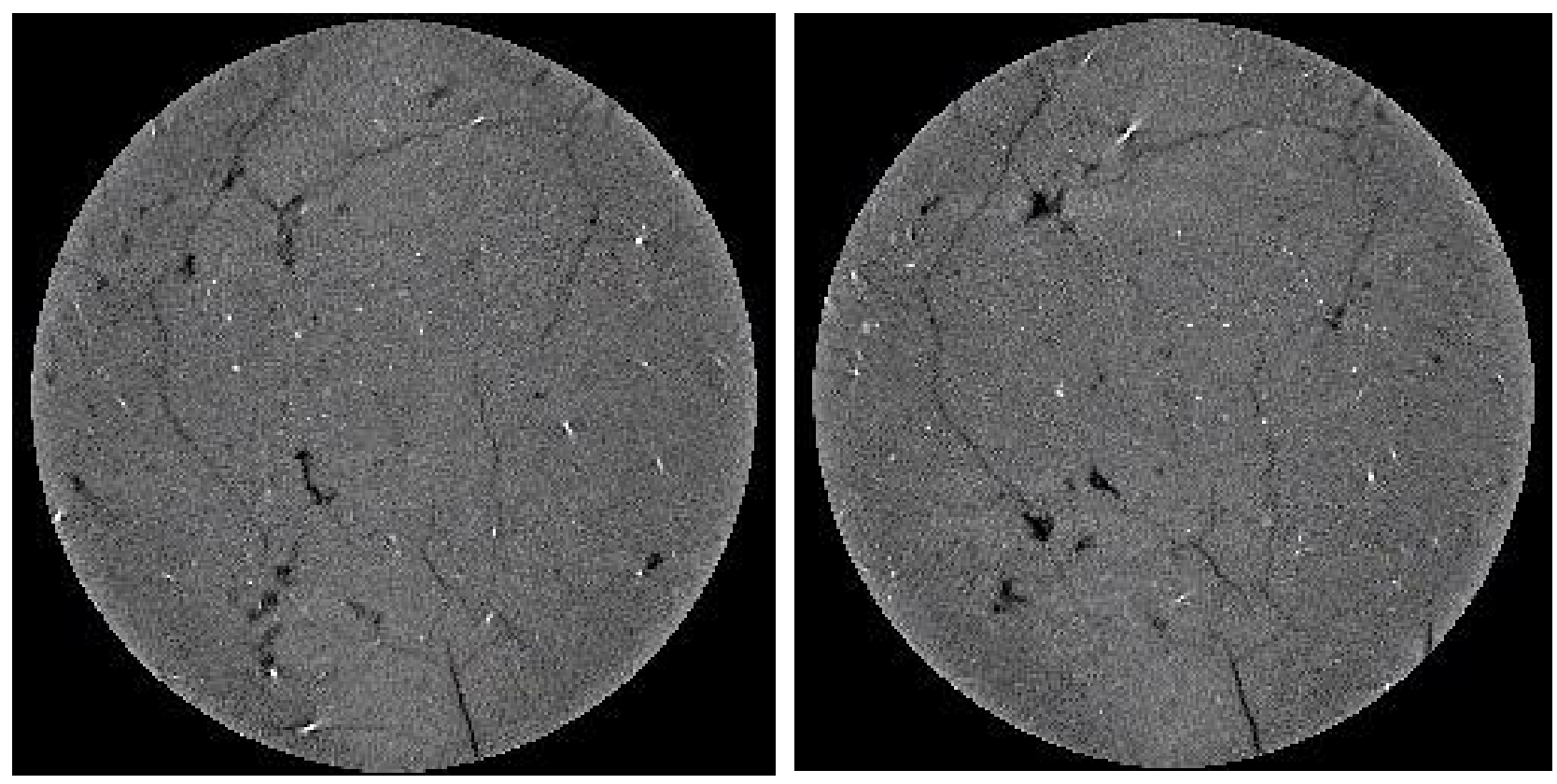

Cross-Section 310

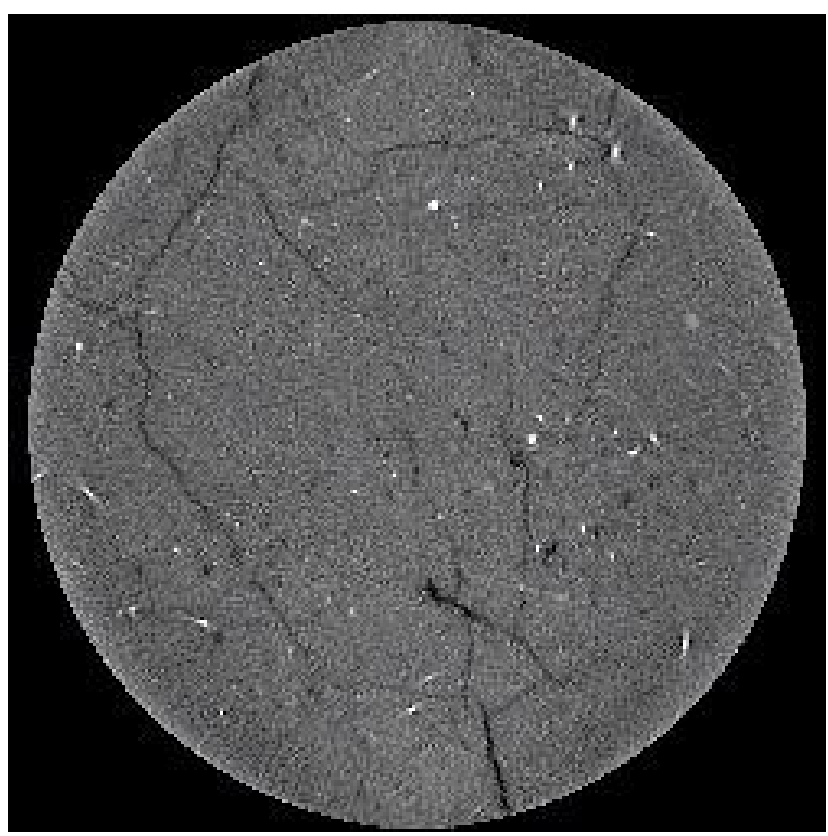

Cross-Section 370
Cross-Section 340

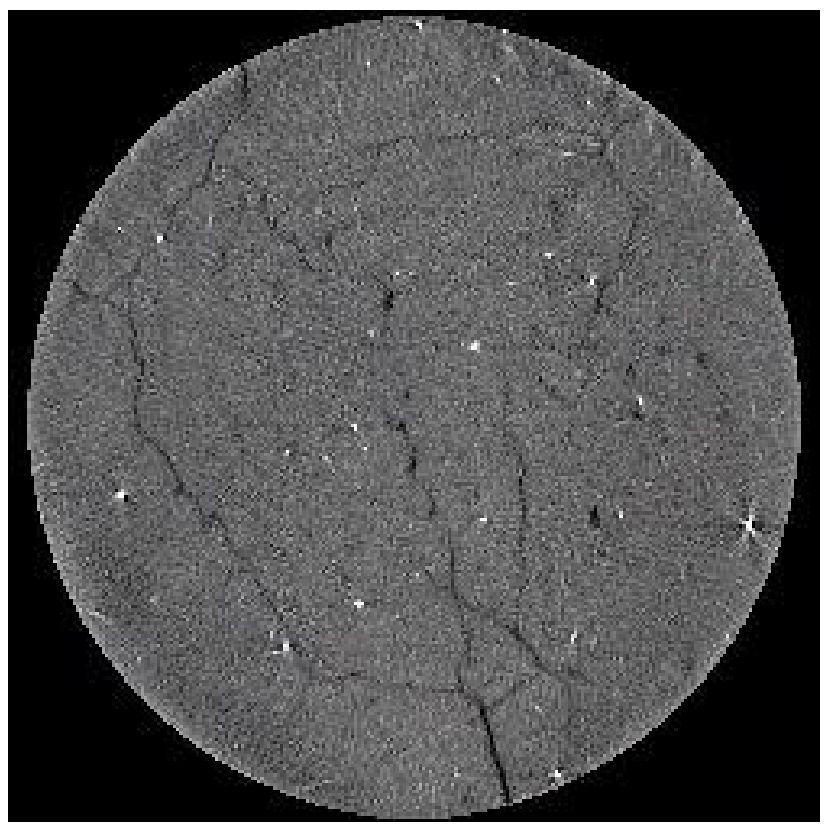

Cross-Section 390

Figure 21 (Continued): X-Ray Tomography Images of Shrinkage Cracks Created by $100 \%$ Ethanol Perfusion Under 15 psi Confining Stress; Cross-Sections Normal to the Axis of the Clay Disk From the Water Side (200) to the Ethanol Side (390). 
A series of parallel cross-sections taken parallel to the axis of the clay disk, with the vertical scale exaggerated to show the cracks in greater detail, are shown in Figure 21. The clay disk at diametral cross-section \#125 is $1 \mathrm{~cm}$. high and $4.7625 \mathrm{~cm}$ (1.875 in.) wide. The cross-sections are of different widths, and grow wider as we move towards the center of the disk at cross-section \#125, because they intersect the disk along a chord of a circle. At the top of each of these images, the sand grains belonging to the water side sand pack can be seen. In these cross-sections, the cracks can be observed to extend from the ethanol side boundary at the bottom towards the water side boundary at the top. While all cracks are wider at the ethanol side, many cracks are seen to completely traverse the thickness of the clay disk and to become thinner towards the water side of the clay disk.

It is possible to quantitatively analyze the crack patterns displayed in these images to obtain statistical information on the crack lengths, crack widths and the crack spacings. From such information, it is possible to estimate the crack flow area fraction, and the contribution of the cracks to the effective permeability of the cracked clay disk. This work is currently underway. Furthermore, the ethanol and water stream connections to the crack propagation cell are currently being shortened to increase the resolution of the X-ray images by reducing the distance between the cell and the X-Ray detector in the imaging window. In this way, a finer level of detail on the crack patterns will be obtained in future experiments to better support predictive analysis of crack generation using computer simulation models. 


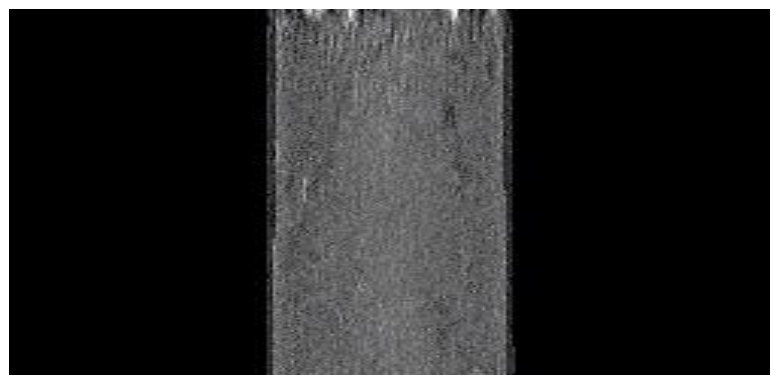

Cross-Section 10

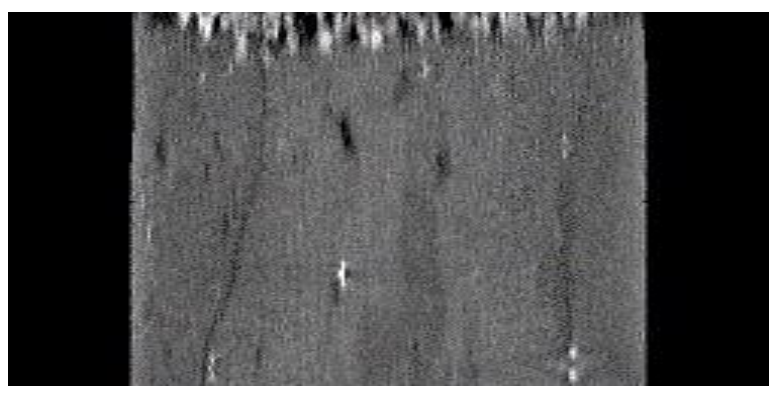

Cross-Section 40

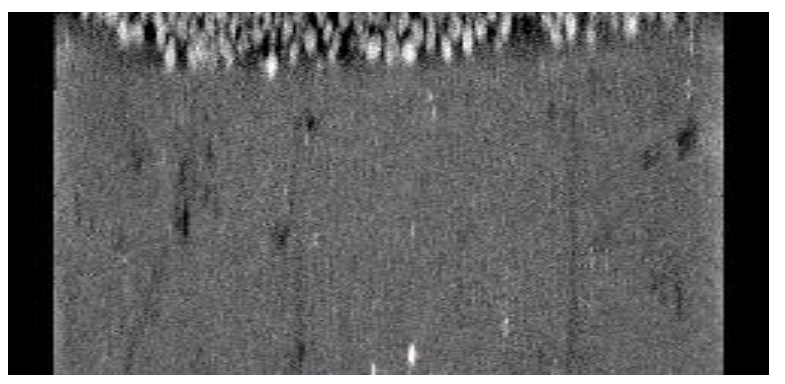

Cross-Section 80

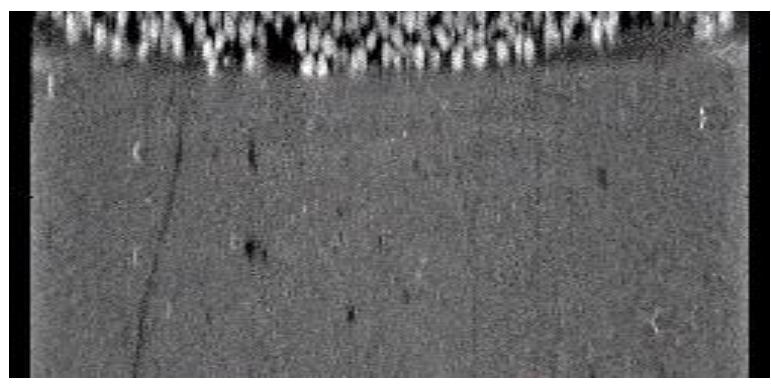

Cross-Section 110

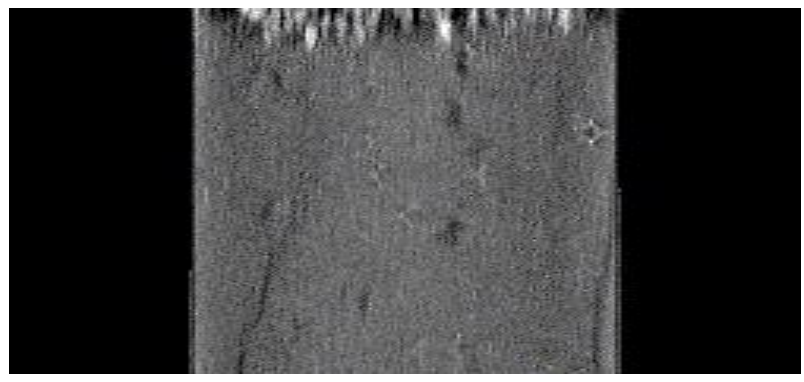

Cross-Section 25

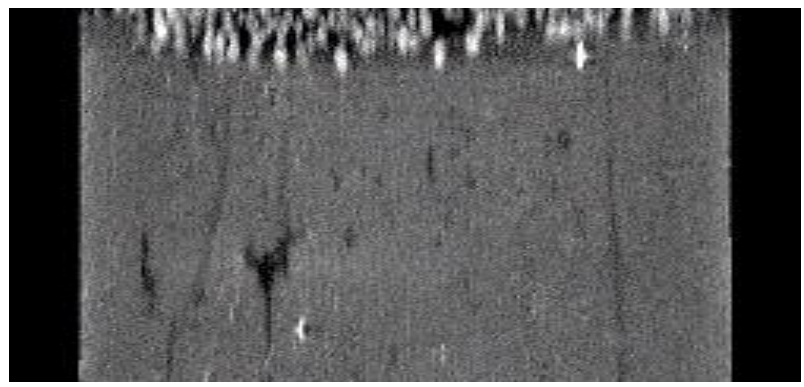

Cross-Section 65

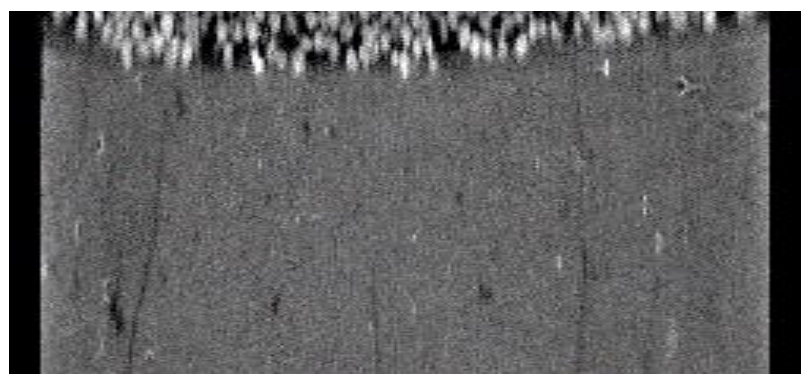

Cross-Section 95

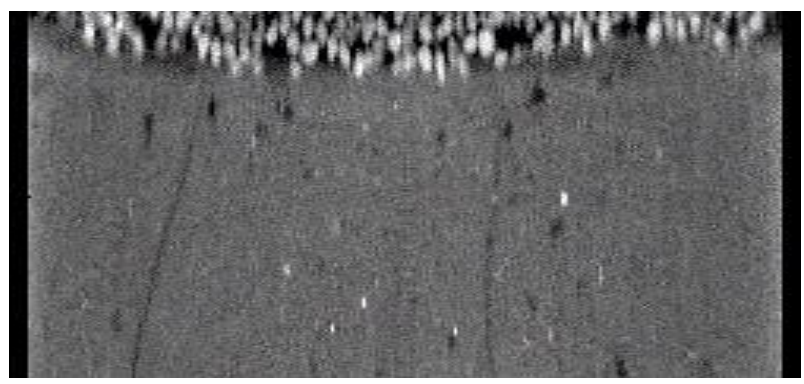

Cross-Section 125 (Center)

Figure 22: X-Ray Tomography Images of Shrinkage Cracks Created by $100 \%$ Ethanol Perfusion Under 15 psi Confining Stress; Cross-Sections Parallel to the Axis of Clay Disk; Water Side at Top of Image. 

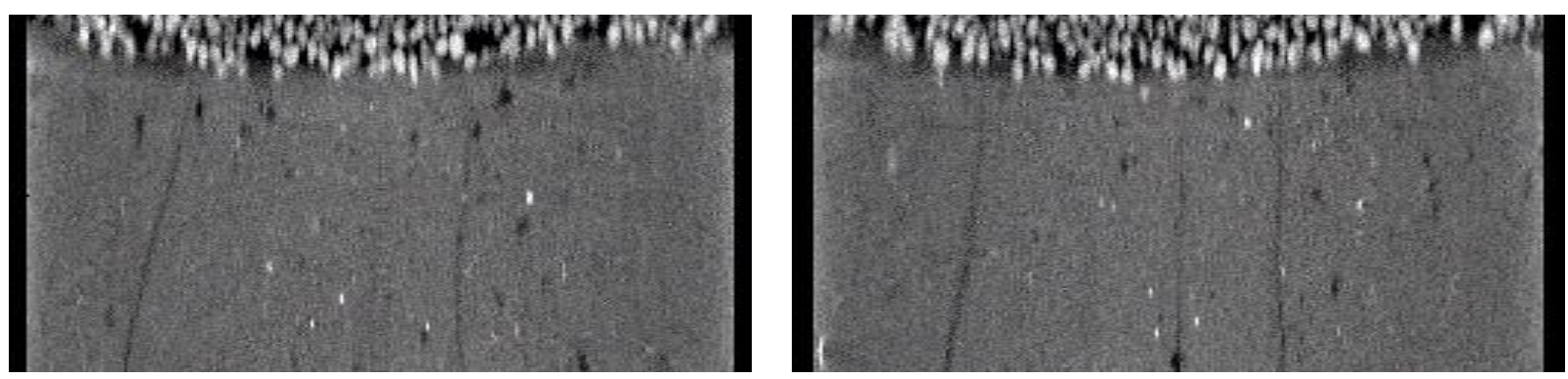

Cross-Section 125 (Center)

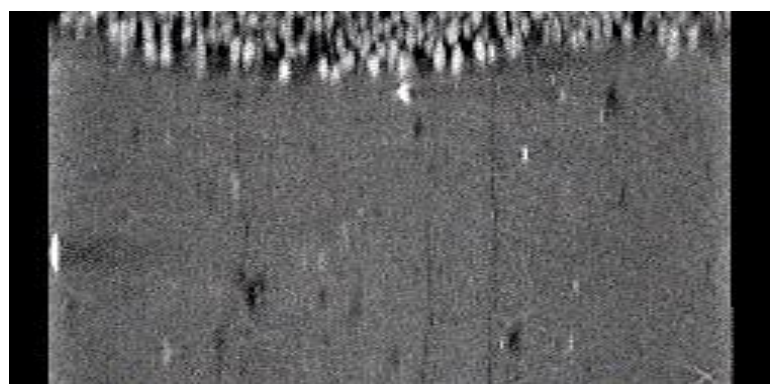

Cross-Section 165

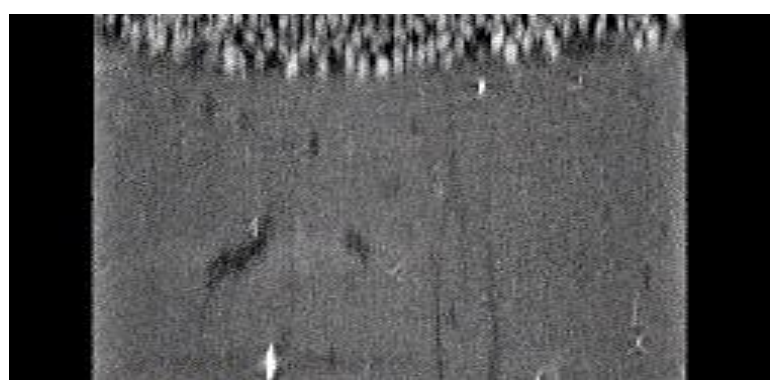

Cross-Section 195

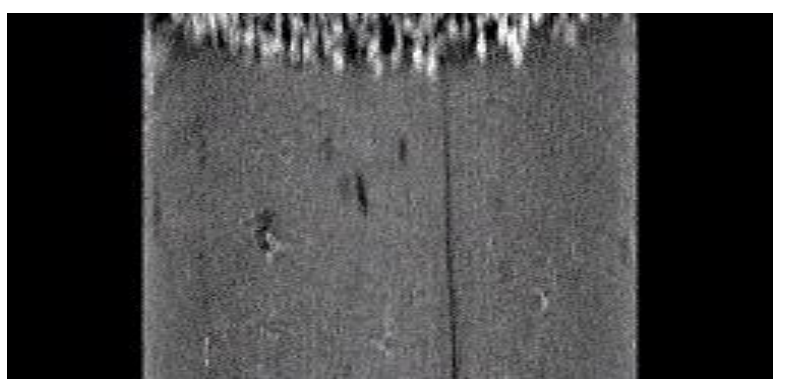

Cross-Section 215
Cross-Section 140

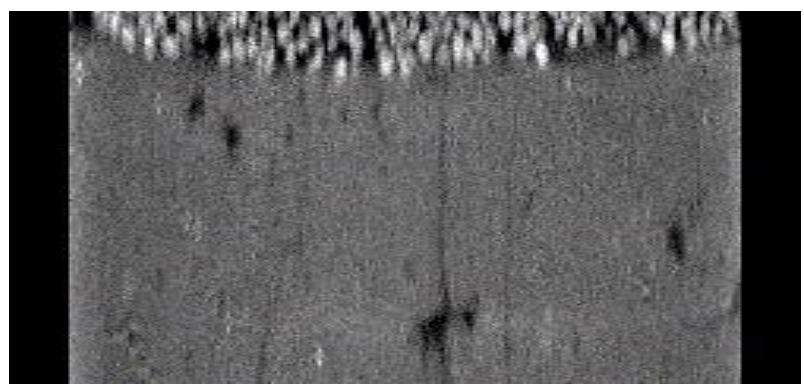

Cross-Section 180

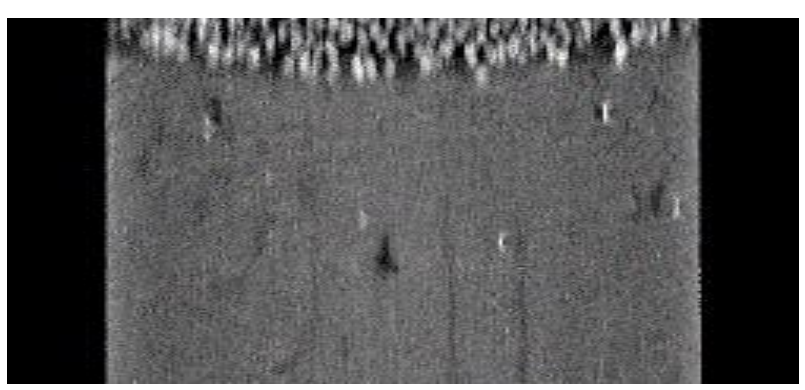

Cross-Section 200

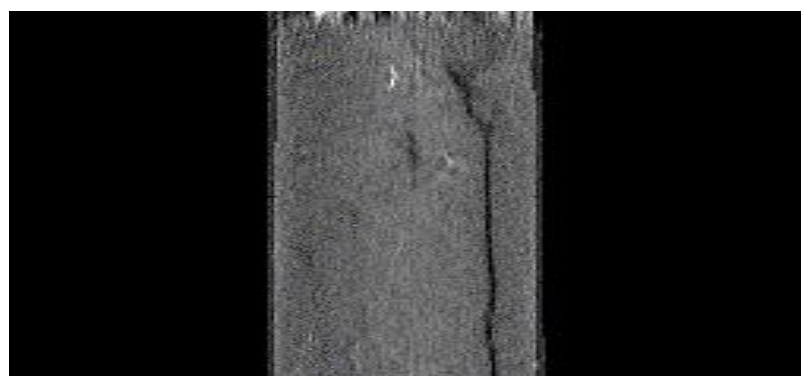

Cross-Section 240

Figure 22 (Continued): X-Ray Tomography Images of Shrinkage Cracks Created by 100\% Ethanol Perfusion Under 15 psi Confining Stress; Cross-Sections Parallel to the Axis of Clay Disk; Water Side at Top of Image. 


\section{SIGNIFICANCE AND CONCLUSIONS}

In this feasibility study, a $1 \mathrm{~cm}$ thick disk of calcium bentonite clay, under 15 psi confining stress, was exposed to pure ethanol on one side of the disk and synthetic Site 300 water on the other side. Although the crack breakthrough time could not be precisely measured because the pressure head applied across the clay layer was too low to overcome blockage by air bubbles, when the applied pressure head was slightly increased, the ethanol solvent broke-through the clay layer from the ethanol side to the water side of the clay disk. The solvent breakthrough was detected and quantified by measuring a high rate of ethanol-water flow through the flow cell and an ethanol fraction in the exit stream that changed from $100 \%$ synthetic Site 300 water to $100 \%$ ethanol. At all times, full liquid saturation within the clay layer was maintained, and drying shrinkage of the clay did not occur. Prior to the solvent breakthrough there was no detectable cumulative mass flow across the clay layer, indicating that the seal at the clay-cell wall did not leak, and that flow through the clay matrix before the cracking was complete was negligible. The Xray images of the clay layer presented here show beyond doubt that many through-going cracks have been created within the clay layer by chemically induced shrinkage of the clay. Preliminary estimates of crack permeability confirm that the flow through the cracks would account for the measured flow rate.

Therefore, we conclude that shrinkage cracks were created in the calcium bentonite clay under confining stress by exposure of the clay to pure ethanol, resulting in a very significant increase in permeability compared to the untreated clay.

However, because the solvent breakthrough time was not determined precisely, this experiment must be repeated to show that the crack propagation through the clay layer occurs much faster than the movement of the solvent diffusion front through an uncracked clay layer. 


\section{FUTURE WORK}

In this feasibility study, we have successfully demonstrated that shrinkage-induced cracks can be created under confining stress to substantially increase the effective permeability of clays. Although an experimental artifact prevented measurement of the exact breakthrough time, visual evidence indicates that the clay layer cracked rapidly in this experiment. We will confirm this in the near future by repeating the experiment.

Much work remains to be done to develop the predictive capability required to reliably design a groundwater remediation process based on this concept. The mechanical deformation properties of finegrained sediments and their swelling/shrinkage properties need to be experimentally measured, and modeled to reflect differences in composition and structural fabric. The interactions between the sediments, the electrochemical properties of the pore fluids and cracking agents such as ethanol and cationic flocculants, and the macroscopic mechanical response that results in cracking, must be experimentally quantified and captured through mathematical models. The maximum depth and confining stress beyond which cracking will not occur must be established for different sediments, and the impact of interference in the cracking process by other fluids and electrolytes that may be present in the groundwater must be assessed. The co-solvency property of solvents such as ethanol, that confer the ability to rapidly desorb, dissolve and mobilize many contaminants that are soluble in water only in trace quantities, must be incorporated in these models.

The success of a remediation technology based on this concept for gaining access to the interiors of fine-grained sediments also hinges on the ability to deliver the cracking agents to target zones without excessive dilution or dispersion that could render the process ineffective and costly. To enhance the efficiency of delivery and reduce the cost of chemicals, small concentrated slugs of the cracking agents can be driven ahead of a bank of injected water, and be protected against breakup and dispersion by graded banks of viscosity modifiers. Such techniques are routinely used in the oil industry in enhanced oil recovery processes. Spent slugs of cracking agents can be captured and pumped to the surface by implementing the process in tailored patterns of injection and extraction wells. The contaminants can be separated from the solvent and water stream at the surface, and the cracking agents recycled for reduced cost and waste generation [3,4]. Additional protection against potential dispersion of mobilized contaminants can be secured by installing metal or slurry barriers to confine and contain the fluids during remediation. Finally, any cracking agents that are used in groundwater applications must be environmentally benign, and residual chemicals left in the subsurface must be easily bio-degraded. In this respect, ethanol is an excellent cracking agent; currently it is the only solvent approved by the EPA for near-surface underground injection [26].

Many additional experiments, including mini-remediation experiments, can be carried out using the current experimental apparatus, with minor modifications if necessary, to perform many of the basic studies that are needed to define and verify the conceptual basis of this technology. With sponsorship of the Environmental Restoration Division (ERD) and the Energy and Environmental Directorate (E\&E), we are currently preparing to submit to internal and external funding sources a number of proposals for undertaking that work. Support will be sought from LLNL's LDRD Program, DOE's EM-50 program, DOD's SERDP program, and through collaborative projects with industrial partners. 


\section{ACKNOWLEDGMENTS}

We wish to convey our deep appreciation to Ken Jackson of LLNL's LDRD Program office and to Bill McConahie of the Environmental Restoration Division for their invaluable assistance and advice during the submittal of this project proposal. We also wish to thank Dorothy Bishop, Fred Hoffman and many others in the Environmental Restoration Division for their support that made this feasibility study of a novel concept a reality.

In addition, we thank Donna McKee, of the Energy and Environmental Directorate (E\&E) for her helpful and efficient assistance in purchasing all materials and equipment for this project, and Carl Boro of E\&E who built the crack propagation and shrinkage measurement cells with his characteristic excellence. Also, we thank Earl Updike of the Manufacturing and Materials Engineering Division (MMED) for performing the X-Ray scanning at short notice, and Dan Schneberk, also of MMED, for generating the XRay tomographic images. We are particularly grateful to Dan for his generosity in making his tomography software available to us, and for teaching us how to use this excellent tool. Finally, we thank Steve Benson of MMED for his assistance in performing the evaluation tests on the ultrasonic imaging technique. 


\section{REFERENCES}

1. National Research Council, Alternatives for Ground Water Cleanup, National Academy Press, Wash. DC, (1994)

2. Barone, F.S., Rowe, R.K, and Quigley, R.M., "A laboratory estimation of diffusion and adsorption coefficients for several volatile organics in natural clayey soil", J. Contam. Hydrol. 10:225-250 (1992)

3. Kansa, E.J., Wijesinghe, A.M., and Viani, B.E. "Nontoxic chemical process for in situ permeability enhancement and accelerated decontamination of fine-grain subsurface sediments" U.S. Patent 5,593,248 (Jan. 14,1997).

4. Kansa, E.J., Anderson, B.L., Wijesinghe, A.M. and Viani, B.E. "Separation of toxic metal ions, hydrophilic hydrocarbons, hydrophobic fuel and halogenated hydrocarbons and recovery of ethanol from a process stream", U.S. Patent 5,906,748 (May 25, 1999).

5. Deryaguin, B.V., Discuss. Faraday Soc. 18, 85 (1954); 42 : 317 (1966).

6. Landau, L.D. and. Lifshitz, W. M., Electrodynamics of Continuous Media, Pergamon, NY (1960).

7. Verwey, E.J.W. and Overbeek, J. Th. 0., Theory of stability of lyophobic colloids, Elsevier, Amsterdam, (1948).

8. Viani, B.E., Low, P.F., and Roth, C.B., "Direct measurement of the relation between interlayer force and interlayer distance in the swelling of montmorillonite", J. Colloid Interface Sci, 96: 229-244 (1983).

9. Fernandez, F. and Quigley, R.M., "Viscosity and dielectric constant controls on the hydraulic conductivity of clayey soils permeated with water-soluble organics", Can. Geotech. J. 25: 582-589 (1988),

10. Brown, K.W., and Thomas, J.C., "A mechanism by which organic liquids increase the hydraulic conductivity of compacted clay materials", Soil Sci. Soc. Am. J., 51:14511459 (1987).

11. Uppot, J.O., and Stephenson, R.W., "Permeability of clays under organic permeants", Geotech. Engr. J. 115:115-131, (1988).

12. Abdul, A.S., Gibson, T.L., and Rai, D.N., "Laboratory studies of the flow of some organic solvents and the aqueous solutions through bentonite and kaolin clays", Groundwater, 28: 524-533 (1990).

13. Bowders, J., "Hydraulic conductivity of compacted clay to dilute organic chemicals", Geotech. Engr. J. 113:1432-1448 (1987).

14. Mitchell, J.K. and Madsen, F.T., "Chemical effects on clay hydraulic conductivity". Proc. Speciality Conf on Geotechnical Practice for Waste Disposal, 1987, ed. Woods, R.D., ASCE, Geotechnical Special Publication 13: 87-116, (1987).

15. Shackelford, C.D. "Waste-soil interactions that alter hydraulic conductivity", in Hydraulic Conductivity and waste contaminant transport in soils, ASTM STP 1142, Daniel, D.E., and Trautwein, S.J. eds. ASTM, Phila, PA (1994).

16. Green, W.J., Lee, G.F., Jones, R.A., and Pallit, T., "Interaction of clay soils with water and organic solvents: Implications for the disposal of hazardous wastes", Environ. Sci. Technol. 17: 278-282 (1983)

17. Murray, R.S., and Quirk, J.P., "Intrinsic failure and cracking of clay", Soil Sci. Soc. Am.3, .54: 11791184(1990).

18. Fang, H-Y, "Cracking and fracture behavior of soil", in Fracture Mechanics applied to Geotechnical Engineering, eds. Vallejo, L.E. and Liang, R. Y., Geotechnical special publication No.43, American Society of Civil Engineers, NY :102-117 (1994).

19. Barone, F.S., Rowe, R.K, and Quigley, R.M., "A laboratory estimation of diffusion and adsorption coefficients for several volatile organics in natural clayey soil”, J. Contam. Hydrl. 10:225-250 (1992)

20. Vinegar, H. J., "X-Ray and NMR imaging of rocks", J. Petroleum Tech., 257-59, (1986). 
21. Roberts, J. J., and Lin, W, "X-ray radiography of fracture flow and matrix imbibition in Topapah Spring Tuff under a thermal gradient", Int. J. Rock Mech.\& Min. Sci., 34:3-4, Paper no. 259, (1997).

22. Bethke, C.M., The Geochemist's Workbench User's Guide, Release 4.0, (2002)

23. Schneberk, D, ImgRec Computer Tomography Software, Personal Communication, LLNL, December 2003.

24. Marimon, M. M., "On the Sorption and Diffusion of Radionuclides in Bentonite Clay," Doctoral Thesis, Department of Chemistry/ Nuclear Chemistry, Royal Institute of Technology, Stockholm, Sweden, 2002, ISRN KTH/KKE-02/1-SE, ISSN 0349-6465, TRITA-KKE-0201.

25. Pusch, R., Waste Disposal in Rock, Elsevier, Amsterdam, Netherlands, 1994. ISBN 0-444-89449-7.

26. LFR Levine-Fricke, "Cosolvent Flushing Pilot Test Report; Former Sages Dry Cleaner," Prepared by LFR Levine-Fricke, 3382 Capital Circle, N.E., Tallahassee, Florida 32308-1568 for Florida Department of Environmental Protection, Twin Towers Office Building, 2600 Blair Stone Road, Tallahassee, Florida 32399-2400, (December 4, 1998). 